\title{
QUIEN BUSCA, ENCUENTRA. ARTE RUPESTRE EN EL SUR DE CHILE: EVALUACIÓN, PERSPECTIVAS Y PREGUNTAS
}

\author{
WHOEVER SEEKS, FINDS. ROCK ART IN SOUTHERN CHILE: \\ ASSESSMENT, PERSPECTIVES, AND QUESTIONS
}

Roberto Campbella, Francisca Moya Cañoles ${ }^{B}$ \& Renata Gutiérrez ${ }^{C}$

El arte rupestre es una evidencia arqueológica que ha sido escasamente estudiada en la zona sur de Chile. En este trabajo damos a conocer los resultados de una investigación, mayormente bibliográfica, que comprende publicaciones científicas, textos de divulgación, notas de prensa, informes técnicos y registros puntuales en terreno. A partir de esto se discuten propuestas previas de definición estilística (estilo Guaiquivilo y "estilo de rostros"), de motivos y técnicas recurrentes ("vulvas" y surcos profundos) y el fenómeno de las piedras santas reportadas etnográficamente para esta zona.

Palabras clave: Arte rupestre, Sur de Chile, Revisión bibliográfica, Guaiquivilo, Estilo de rostros.

As archaeological evidence, rock art has been scarcely studied in the south of Chile. This paper presents the research results of a mostly bibliographical review, which includes scientific publications, informational texts, press releases, and technical reports, as well as specific field records. Based on this, we discuss previous proposals of stylistic definitions (Guaiquivilo style and 'face' style), of motifs and recurrent techniques ('vulvas' and deep lines), and the sacred stones phenomenon ethnographically reported for this area.

Keywords: Rock art, Southern Chile, Bibliographical review, Guaiquivilo, Face style.

\section{INTRODUCCIÓN}

$\mathrm{El}$ arte rupestre del sur de Chile $\left(36^{\circ}-42^{\circ} \mathrm{S}\right)$ nunca ha ocupado profusamente un espacio en las discusiones arqueológicas en Sudamérica, o incluso en Chile (Iribarren 1973a; Niemeyer 1975, 1979; Mostny \& Niemeyer 1983; Aldunate et al. 1985; Berenguer 1986; Sepúlveda \& Valenzuela 2012; Sepúlveda et al. 2016; Troncoso et al. 2017, 2018). Esto no sorprende, pues su registro es muy escaso en comparación con zonas circunvecinas como el norte semiárido chileno $\left(26^{\circ}-32^{\circ} \mathrm{S}\right)$ (Iribarren 1973b, Ampuero 1985, Cervellino 1985, Jackson et al. 2001, Niemeyer \& Ballereau 1998, 2004, Troncoso et al. 2008), la Patagonia septentrional (Schobinger 1956, Fernández 2000, Romero \& Re 2014, Blanco et al. 2015, Romero 2016, Labarca et al. 2016, Barberena et al. 2017) o la Patagonia central y meridional (Menghin 1957; Bate 1970, 1971; Lucero \& Mena 2000; Artigas \& Muñoz 2015). Sin embargo, aquella parece ser una situación compartida con casi todo Chile central $\left(32^{\circ}-36^{\circ} \mathrm{S}\right)$, particularmente desde el río Tinguiririca al sur $\left(34,5^{\circ} \mathrm{S}\right)$.

En nuestro caso, el interés por el arte rupestre del sur de Chile -y germen de este trabajo- se origina en la

\footnotetext{
A Roberto Campbell, Escuela de Antropología, Facultad de Ciencias Sociales, Pontificia Universidad Católica de Chile. Av. Vicuña Mackenna 4860, Macul, Santiago. Chile. E-mail: roberto.campbell@uc.cl

B Francisca Moya Cañoles, SERP/Departament d'Història i Arqueologia, Universitat de Barcelona. C/ Montalegre 6-8, 08001, Barcelona, España. E-mail: frmoyaca7@alumnes.ub.edu

C Renata Gutiérrez, Institute of Archaeology, University College London. Reino Unido. E-mail: renatags@gmail.com
} 
investigación iniciada en 2016 en Cueva de los Catalanes (Región de la Araucanía, 37,8 S) (fig. 1). En dicho sitio el registro de arte rupestre realizado por nosotros (Gutiérrez 2016, Gutiérrez \& Moya 2017) nos enfrentó a una evidencia heterogénea y compleja, mucho más de lo que Menghin (1959-1960) y Berdichewsky (1968) habían reportado originalmente. Esto nos supuso el desafío adicional de no contar con información clara y sistematizada a nivel regional. De hecho, el carácter altamente disgregado de la evidencia en términos geográficos hace que una perspectiva regional sea seguramente la más idónea en esta etapa de la investigación.

En este trabajo presentamos una sistematización del arte rupestre del sur de Chile a partir de una revisión mayormente bibliográfica. En primer lugar, exponemos la metodología diseñada para esta revisión, detallando las características de la zona bajo estudio, la diversidad de fuentes bibliográficas utilizadas, así como también las unidades y variables empleadas en el análisis. En segundo lugar, entregamos una breve reseña histórica de las investigaciones en la región. Luego, abordamos los resultados del análisis sobre distribución, cronología, asociaciones materiales, iconografía y tecnología de estas manifestaciones. Finalmente, consideramos la discusión acerca de algunas propuestas desarrolladas por otros investigadores y planteamos líneas para futuras investigaciones.

\section{ÁREA DE ESTUDIO Y METODOLOGÍA}

La investigación se estructuró inicialmente desde una revisión bibliográfica que nos permitiese poner en contexto el arte rupestre de Cueva de los Catalanes. Para ello se consideró el registro presente en todo el sur de Chile (Aldunate 1989), área que abarca las Regiones de Nuble, Biobío, La Araucanía, Los Ríos y Los Lagos hasta el canal de Chacao, cubriendo $111.440 \mathrm{~km}^{2}$ y $650 \mathrm{~km}$ lineales de norte a sur (fig. 1). La zona está caracterizada por

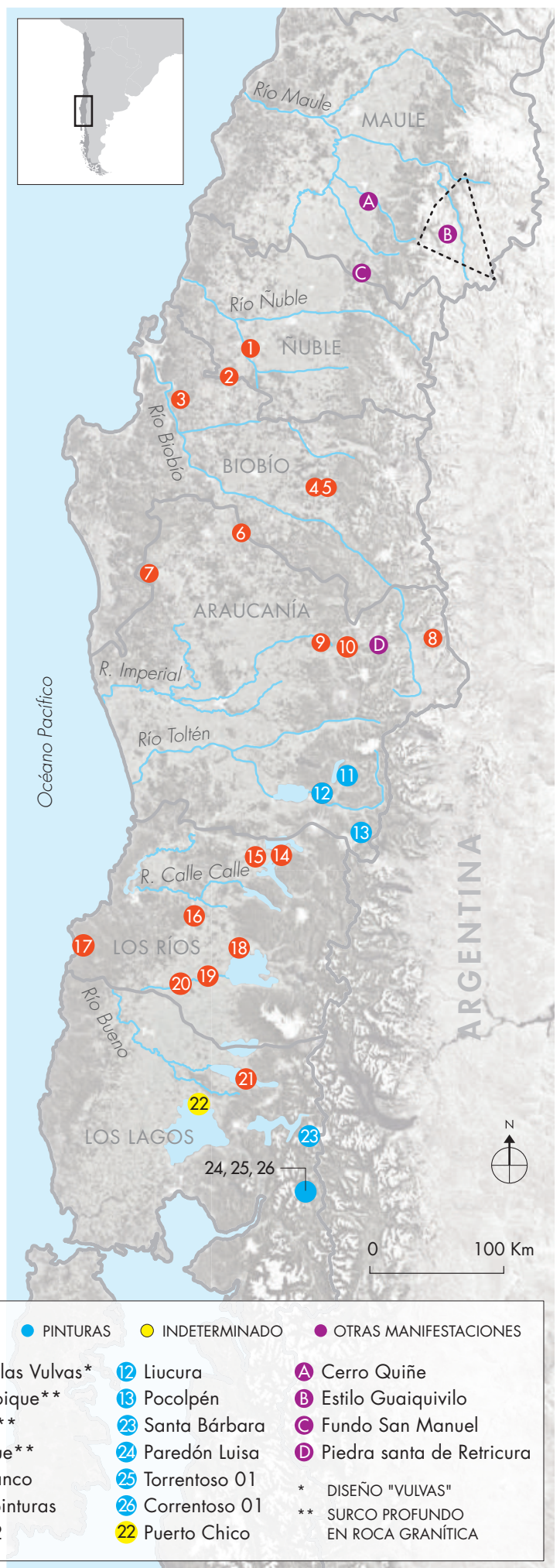

Figura 1. Mapa de los sitios de arte rupestre del sur de Chile. Figure 1. Map of the rock art sites of southern Chile. 
un clima templado que, de norte a sur, va transitando desde un tipo Csb a uno Cfb predominantes (Sarricolea et al. 2018). Asimismo, hay una progresión latitudinal desde una vegetación esclerófila a una caducifolia, y finalmente laurifolia y siempreverde (Gajardo 1994, Luebert \& Pliscoff 2006), la que ha sido severamente impactada en tiempos históricos (Lara et al. 2012). Geomorfológicamente, la zona está formada por cinco macroformas longitudinales: la planicie costera y sus islas adyacentes, la cordillera de la Costa, la Depresión Intermedia o Valle Central, la precordillera o montaña, y la cordillera de los Andes (Börgel 1983).

Es importante señalar que se relevaron como "arte rupestre" aquellos casos que fueron indicados por las fuentes como arte rupestre (o como petroglifos, pinturas, pictografías o grabados), reconociendo en este la intención clara de representar un diseño en particular. Por tanto, la información de aquellas otras manifestaciones que también conllevan la modificación de un soporte pétreo, pero que no presentan diseños reconocibles sobre sus superficies, si bien también fueron relevadas, no fueron incorporadas directamente en esta evaluación. Tal es el caso de las piedras tacitas y de algunas de las llamadas piedras santas.

Se revisaron 41 fuentes, las cuales comprenden un lapso temporal cercano a los 150 años (1870-2018). Este aspecto presentó la dificultad de aproximarse a fuentes muy heterogéneas en cuanto a calidad de la información; desde trabajos académicos dedicados a un caso particular con ubicación, descripciones y fotografías (p. e., Oyarzún 1910), hasta otras que son solo una breve mención (p. e., Guevara 1911), o incluso solo un punto en un mapa (p. e., Van de Maele 1968). Entre dichas fuentes se incluyen también notas de prensa aparecidas en diarios y revistas nacionales, referidas por Menghin (1964), Niemeyer y Montané (1968) y Stehberg (1980); sin embargo, no pudimos dar con todas estas, dado lo parcial de algunas referencias. Finalmente se consideraron trabajos fruto de proyectos patrimoniales realizados en la última década (Piedra de Reunión 2011, Espinoza 2017), investigaciones pseudo-arqueológicas (Fonck 1965) y distintos sitios webs.

Este trabajo de gabinete fue acompañado por registros en terreno de algunos de los puntos identificados (Villucura-pinturas, Petroglifos del Llaima, Cerro de la Piedra con Costilla, Paredón Luisa), los que se suman a lo realizado en Cueva de los Catalanes. En otros casos, dicha iniciativa fue infructuosa (Purén-Pangueco,
Villucura-petroglifo); sin embargo, su búsqueda permitió acotar el área de ubicación de los mismos, a partir de las indicaciones de los lugareños.

Por lo dicho anteriormente, nuestra evaluación se basa, en la mayoría de los casos, en descripciones, fotografías, dibujos, mapas y croquis disponibles, los que, como se señaló, no siempre fueron generados por investigadores ni con fines de difusión o registro. En este sentido, las referencias más recientes -décadas del 2000 y 2010 - son mucho más ricas y precisas, dado un mayor acceso a instrumentos para su registro (p. e., GPS, fotografías digitales).

La información relevada se consideró a partir de sitio, soporte y motivo o diseño, analizándola desde diversas variables. Para los sitios se analizó la frecuencia, ubicación (región, comuna), macroforma, tipo de sitio ("cielo abierto" o "reparo" [alero o cueva]), evidencias arqueológicas asociadas, intervenciones arqueológicas, cronología e interpretación del contexto. En cuanto a los aleros y cuevas en cuyas superficies se haya registrado arte rupestre, se los consideró como un único bloque, entendiéndolos como una sola unidad pétrea. En el caso de los soportes, se tomó en cuenta litología, número de motivos y técnica.

Por último, asumimos como sinónimos los conceptos de motivo y diseño, entendiéndolos como una unidad de conceptos de representación visual. Por ello se los usa intercambiablemente en este trabajo. Lo anterior constituye una decisión conceptual diferente a lo indicado por Fiore (2011: 111), pues debido a la escasa información que presentaron algunas de las fuentes bibliográficas consultadas, no fue posible analizar la composición visual y segregar los diseños en unidades compositivas más específicas. Dicho esto, se relevó en este caso el tipo de motivo (figurativo, no figurativo), frecuencia, técnica, color del trazo, tipo de surco y morfología. La información cuantitativa que presentamos se basó principalmente en lo que exponen sus autores, incluidas fotografías y dibujos. Se desestimaron los datos presentados como dudosos por los autores. Por esta razón, el número de bloques y motivos se debe considerar como un número mínimo, pues no se puede asegurar que aquellas cantidades no aumenten con la realización de un registro sistemático en terreno. 


\section{RESEÑA HISTÓRICA}

La primera referencia respecto de la existencia de arte rupestre en el sur de Chile parece haber sido dada por Fonck (1870: 287), quien menciona unas líneas y signos inentendibles hallados en las paredes de una cueva en el lago Llanquihue. Sin embargo, este trabajo y su información, como hace notar Menghin (1964: 380), pasaron totalmente desapercibidos para investigadores inmediatamente posteriores, como Latcham, Plagemann y Oyarzún, e incluso hasta el día de hoy.

Por tanto, exceptuando dicha aislada e inadvertida mención, bien podemos decir que al inicio del siglo xx, la evidencia más austral conocida académicamente de arte rupestre en Chile -sin considerar la de Patagonia central y meridional- correspondía a Casa Pintada, en la cordillera del río Tinguiririca $\left(34,8^{\circ} \mathrm{S}\right.$ ) (Stolp 1889 , Barros Grez 1900, Domeyko 1903, Niemeyer \& León 2001). Es decir, para la zona objeto de nuestro trabajo no existía ningún reporte con respecto a su presencia. Lo anterior queda bien ejemplificado en el trabajo de síntesis sobre el arte rupestre de Chile que realiza Plagemann (1906). ${ }^{1}$ De hecho, el hoy clásico trabajo de Oyarzún (1910) sobre los petroglifos del Llaima está particularmente dirigido a refutar a aquel investigador y a otros (Medina 1882, Barros Arana 1884), toda vez que ellos veían en la ausencia de arte rupestre un claro reflejo del bajo nivel cultural alcanzado por las poblaciones al sur del límite austral de las influencias andinas o del dominio incaico. Este trabajo resulta ser la primera investigación sobre un sitio con arte rupestre en todo el sur de Chile y uno de los primeros de corte antropológico-arqueológico de este destacado investigador. Adicionalmente, será en este trabajo en el que Oyarzún, al querer interpretar los mencionados petroglifos, propondrá por primera vez a nivel local que, aquel motivo correspondiente a "una figura elíptica, vertical, en forma de herradura cerrada con la base hacia arriba" (1910: 42) corresponde a "vulvas", vinculándolo a su vez a ritos de fertilidad. ${ }^{2}$

Casi contemporáneamente a Oyarzún, pero sin el mismo grado de detalle, Guevara (1911: 214, 218; 1916: 176) menciona bloques rocosos con modificaciones culturales, algunos de los cuales corresponden ciertamente a arte rupestre. Entre estos últimos alude a los Petroglifos del Llaima, aunque indicando que están siendo estudiados por Oyarzún. No está demás decir que los trabajos de Guevara evidencian clara- mente la dificultad metodológica, también presente en Cañas Pinochet (1902), de segregar el arte rupestre de aquellas otras manifestaciones como piedras tacitas y piedras santas.

Para las décadas que siguen a los trabajos pioneros de Oyarzún y Guevara, se observa el constante hallazgo de nuevas manifestaciones rupestres. La mayoría de ellos -por no decir todos- serán descubrimientos fortuitos, producto de otras actividades de investigación o bien siguiendo la pista de notas de prensa o de informaciones locales que llegaron a oídos de investigadores. De esta forma, en la década de 1930 contamos con los trabajos de De la Cerda (1935) y Oliver Schneider (1935), y en la de 1950 el de Menghin (1959-1960).

La década de 1960 y hasta inicios de la de 1980 fue pródiga en nuevos hallazgos, síntesis, re-evaluaciones y propuestas. Niemeyer y Montané (1968) generaron la primera evaluación del arte rupestre del centro-sur de Chile, abarcando desde la Provincia de Aconcagua hasta la de Osorno. Dicha evaluación considera tanto las fuentes académicas disponibles como las notas de prensa (Diario Ilustrado, El Mercurio, Vea, Ercilla). En la zona de nuestro interés refieren solo seis puntos: Cerro de la Piedra con Costilla, Villucura-petroglifo, Villucurapinturas, Cueva de los Catalanes, Petroglifos del Llaima, Cachillahue y Lago Rupanco. Como los mismos autores señalan, con excepción de ambos Villucura (Montané 1965-1966), ninguno de estos sitios fue visitado por ellos. A estos trabajos debemos agregar las investigaciones puntuales de Van de Maele $(1966,1968)$.

En aquellas dos décadas aparecieron también nuevas síntesis del arte rupestre chileno (Iribarren 1973a; Niemeyer 1975, 1979; Mostny \& Niemeyer 1983), como también el Diccionario de sitios arqueológicos de Araucanía (Stehberg 1980). Estos, con mayor o menor detenimiento, incluyeron los sitios con arte rupestre del sur de Chile. También contamos con los trabajos de Inostroza et al. (1983, 1984), los que fueron parte de un proyecto del Museo Regional de la Araucanía referido al arte rupestre regional (Museo Regional de la Araucanía 1985: 4). Paralelamente, hubo esfuerzos por re-localizar o re-evaluar algunos de los sitios identificados en el pasado. Entre estos está Villalón (1964), Berdichewsky (1968) y Gordon (1980, 1982). ${ }^{3}$

Este momento de la investigación es clave además, pues introduce varias ideas que aún permean la reflexión referida al arte rupestre del sur de Chile. Una de ellas es la propuesta de Niemeyer y Montané (1968: 435, 
445), basada en la evidencia de Cerro de la Piedra con Costilla y Cachillahue, de un "estilo de rostros" para el área araucana. Este estilo, sin embargo, no es descrito explícitamente por ellos, sino que dicha tarea será llevada a cabo por Mostny y Niemeyer (1983), quienes usando los mismos casos, dirán que se define por una técnica de "surco profundo o inscultura con que se han grabado algunos grandes peñascos. La temática se orienta a reproducir rostros o figuras que parecen rostros, algunos probablemente de búhos o lechuzas" (1983: 77).

Otro planteamiento surgido también en esta época es acerca del estilo Guaiquivilo, el que, si bien se ubica fuera de nuestra zona de estudio -área cordillerana de la Región del Maule- ha sido relevante para la interpretación del arte rupestre del sur de Chile. Este estilo es propuesto por Niemeyer y Weisner (1972-1973) y corresponde a conjuntos de motivos abstractos y figurativos en técnicas de grabado que se emplazan sobre grandes planchones rocosos horizontales; ellos le atribuyen una cronología ubicada entre los siglos XII y XVI DC.

Por su parte, Gordon (1980), pero más claramente Mostny y Niemeyer (1983), hacen hincapié en una aparente recurrencia regional de la técnica de grabado de surco profundo, la que se manifestaría en Cerro de la Piedra con Costilla, Cachillahue y Petroglifos del Llaima. Por último, Gordon (1980), a partir de su trabajo en Petroglifos del Llaima, también re-actualiza la idea del motivo de "vulva" propuesto originalmente por Oyarzún (1910), planteándolo como un posible elemento transversal al arte rupestre del sur de Chile, dada su presencia tanto aquí como en Cueva de los Catalanes, Los Peñascos y Purén-Pangueco.

Desde la década de 1990 en adelante aparecen trabajos que reportan el hallazgo de nuevos sitios de arte rupestre, algunos de ellos producto de estudios de impacto ambiental (EIA). En este sentido, referimos a Vergara $(1990,1991)$, Adán et al. $(2005,2007)$, Castelleti (2007), García (2007), Mera y Munita (2008), Podestá et al. (2008) y Dillehay y Ocampo (2016).

Finalmente, no podemos dejar de señalar iniciativas recientes vinculadas a aspectos de patrimonio, conservación o turismo, las que han permitido actualizar y complementar la información existente para algunos puntos. Entre estas están aquellas de la Piedra de Reunión (2011), Espinoza (2017) y algunos sitios webs.

Dada esta breve historia de hallazgos y reportes, debiésemos esperar el descubrimiento en el futuro de nuevos puntos con arte rupestre en el sur de Chile. No deja de ser significativo el incremento que ocurre desde 1990, a la par de un aumento en los proyectos de investigación como también de los EIA. Sin embargo, como se señaló previamente, parece claro que la presencia de arte rupestre no es aquí particularmente abundante, en comparación con Patagonia septentrional o el norte semiárido chileno.

\section{RESULTADOS}

\section{Distribución, características y cronología de los sitios de arte rupestre}

Para el sur de Chile $\left(36^{\circ}-42^{\circ} \mathrm{S}\right)$ pudimos identificar 26 puntos que reportaban la presencia de arte rupestre (tabla 1 y fig. 1). Estos se distribuyen de manera dispersa a lo largo de todas las macroformas longitudinales, concentrándose catorce en la precordillera y cordillera de los Andes.

De los sitios reconocidos, 11 corresponden a reparos rocosos de diferentes tamaños. Por una parte, hay cuatro cuevas: Panguipulli, Cueva de los Catalanes, Cueva de las Vulvas y Puerto Chico. Entre los aleros rocosos de menor tamaño se encuentran Villucura-pinturas, Pocolpén, Renahue 2, Santa Bárbara 1, Torrentoso 01, Correntoso 01 y Paredón Luisa. Los restantes sitios están a cielo abierto, excepto cuatro (Hueñivales, Liucura, Lipingue, Lago Rupanco), para los cuales la información no permite abordar este aspecto. A partir de la evidencia obtenida en terreno (Villucura-pinturas, Petroglifos del Llaima, Cerro de la Piedra con Costilla, Paredón Luisa), se comprueba que el soporte material utilizado ha sido arenisca y granito.

De lo anterior se desprende que el emplazamiento de los sitios no siempre es descrito en detalle; sin embargo, la información existente nos permite plantear que es muy diverso, pues hay sitios que se encuentran en terrazas fluviales (p. e., Cachillahue), en laderas de cerro (p. e., Torrentoso 01), así como en cimas de cerro (p. e., Cerro de la Piedra con Costilla).

La mayoría de los sitios analizados $(\mathrm{N}=16)$ refieren a un solo bloque, dos de ellos tendrían dos bloques (Petroglifos del Llaima, Cachillahue), y uno de ellos tres bloques (Cerro de la Piedra con Costilla) (tabla 1). En el resto no fue posible identificar el número de bloques, aunque en el caso de Paso Hondo, Huanehue y Hueñivales los autores hablan de rocas en plural, lo que indica que 
Tabla 1. Sitios de arte rupestre del sur de Chile. Table 1. Rock art sites of southern Chile.

\begin{tabular}{|c|c|c|c|c|c|c|c|}
\hline $\begin{array}{l}\mathrm{N}^{\circ} \text { EN } \\
\text { FIG. } 1\end{array}$ & SITIO & $\begin{array}{l}\text { UBICACIÓN } \\
\text { (región, comuna) }\end{array}$ & $\begin{array}{l}\text { MACROFORMA } \\
\text { LONGITUDINAL }\end{array}$ & TÉCNICA & $\begin{array}{l}\text { TIPO DE } \\
\text { SITIO }\end{array}$ & $\begin{array}{l}\text { № MÍNIMO } \\
\text { DE BLOQUES }\end{array}$ & REFERENCIAS \\
\hline 1 & Los Peñascos ${ }^{A}$ & Ñuble, Bulnes & $\begin{array}{l}\text { Depresión } \\
\text { Intermedia }\end{array}$ & Grabado & $\begin{array}{l}\text { Cielo } \\
\text { abierto }\end{array}$ & 1 & $\begin{array}{c}\text { Gordon 1980: } 71 \\
\text { Stehberg 1980: } 84 \text {, } \\
\text { 151-152 } \\
\text { Vergara 1990 } \\
\text { (con figuras) }\end{array}$ \\
\hline 2 & Paso Hondo & $\begin{array}{l}\text { Ñuble, } \\
\text { Quillón }\end{array}$ & $\begin{array}{l}\text { Depresión } \\
\text { Intermedia }\end{array}$ & Grabado & $\begin{array}{l}\text { Cielo } \\
\text { abierto }\end{array}$ & Más de 1 & $\begin{array}{l}\text { Vergara } 1991 \\
\text { (con figuras) }\end{array}$ \\
\hline 3 & $\begin{array}{l}\text { Cerro de la Piedra } \\
\text { con Costilla }\end{array}$ & $\begin{array}{l}\text { Biobío, } \\
\text { Hualqui }\end{array}$ & $\begin{array}{l}\text { Cordillera de } \\
\text { la Costa }\end{array}$ & Grabado & $\begin{array}{l}\text { Cielo } \\
\text { abierto }\end{array}$ & 3 & $\begin{array}{l}\text { De la Cerda } 1935 \\
\text { (con figuras) } \\
\text { Oliver Schneider } \\
1935 \\
\text { Villalón } 1964 \\
\text { (con figuras) } \\
\text { Espinoza 2017 } \\
\text { (con figuras) }\end{array}$ \\
\hline 4 & Villucura-petroglifo ${ }^{B}$ & $\begin{array}{c}\text { Biobío, Santa } \\
\text { Bárbara }\end{array}$ & Precordillera & Grabado & $\begin{array}{l}\text { Cielo } \\
\text { abierto }\end{array}$ & 1 & $\begin{array}{l}\text { Montané 1965-1966 } \\
\text { (con figuras) }\end{array}$ \\
\hline 5 & Villucura-pinturas & $\begin{array}{l}\text { Biobío, Santa } \\
\text { Bárbara }\end{array}$ & Precordillera & Pintura & Reparo & 1 & $\begin{array}{l}\text { Montané 1965-1966 } \\
\text { (con figuras) }\end{array}$ \\
\hline 6 & $\begin{array}{c}\text { Cueva de los } \\
\text { Catalanes }\end{array}$ & $\begin{array}{l}\text { Araucanía, } \\
\text { Collipulli }\end{array}$ & $\begin{array}{l}\text { Depresión } \\
\text { Intermedia }\end{array}$ & Grabado & Reparo & 1 & $\begin{array}{c}\text { Menghin 1959-60: } \\
\text { 69-70 (con figuras) } \\
\text { Berdichewsky 1968: } \\
\text { 36-37, 41, 44, 77-79 } \\
\text { (con figuras) } \\
\text { Gutiérrez 2016 } \\
\text { (con figuras) } \\
\text { Gutiérrez \& Moya } \\
2017 \text { (con figuras) }\end{array}$ \\
\hline 7 & Purén-Pangueco ${ }^{\mathrm{C}}$ & $\begin{array}{l}\text { Araucanía, } \\
\text { Purén }\end{array}$ & $\begin{array}{l}\text { Cordillera de } \\
\text { la Costa }\end{array}$ & Grabado & $\begin{array}{l}\text { Cielo } \\
\text { abierto }\end{array}$ & ND & $\begin{array}{c}\text { Gordon 1980: 64 } \\
\text { Museo Regional de } \\
\text { la Araucanía 1985: } 4 \\
\text { Lara 2014 } \\
\text { (con figuras) }\end{array}$ \\
\hline 8 & Maloñehue 1 & $\begin{array}{l}\text { Araucanía, } \\
\text { Lonquimay }\end{array}$ & $\begin{array}{l}\text { Cordillera de } \\
\text { los Andes }\end{array}$ & Grabado & $\begin{array}{l}\text { Cielo } \\
\text { abierto }\end{array}$ & 1 & $\begin{array}{l}\text { Inostroza et al. } 1983 \\
\text { (con figuras) } \\
\text { Inostroza et al. } 1984 \\
\text { (con figuras) }\end{array}$ \\
\hline 9 & $\begin{array}{l}\text { Petroglifos del } \\
\text { Llaima }\end{array}$ & $\begin{array}{l}\text { Araucanía, } \\
\text { Curacautín }\end{array}$ & Precordillera & Grabado & $\begin{array}{l}\text { Cielo } \\
\text { abierto }\end{array}$ & 2 & $\begin{array}{c}\text { Oyarzún } 1910 \\
\text { (con figuras) } \\
\text { Gordon } 1980 \\
\text { (con figuras) } \\
\text { Gordon } 1982 \\
\text { Piedra de Reunión } \\
\text { 2011: } 4 \text { (con figuras) }\end{array}$ \\
\hline 10 & Hueñivales & $\begin{array}{l}\text { Araucanía, } \\
\text { Curacautín }\end{array}$ & Precordillera & Grabado & $?$ & Más de 1 & $\begin{array}{c}\text { Guevara 1911: } \\
218,250 \\
\text { Guevara 1916: } 176\end{array}$ \\
\hline 11 & Renahue $2^{\mathrm{D}}$ & $\begin{array}{l}\text { Araucanía, } \\
\text { Pucón }\end{array}$ & $\begin{array}{l}\text { Cordillera de } \\
\text { los Andes }\end{array}$ & Pintura & Reparo & 1 & $\begin{array}{l}\text { González 1986: } \\
\text { 25-27 (con figuras) } \\
\text { Castelleti 2007 } \\
\text { (con figuras) }\end{array}$ \\
\hline 12 & Liucura $^{\mathrm{E}}$ & $\begin{array}{l}\text { Araucanía, } \\
\text { Pucón }\end{array}$ & $\begin{array}{l}\text { Cordillera de } \\
\text { los Andes }\end{array}$ & Pintura & $?$ & ND & $\begin{array}{c}\text { Inostroza \& Sánchez } \\
\text { 1994: } 115\end{array}$ \\
\hline 13 & Pocolpén & $\begin{array}{l}\text { Araucanía, } \\
\text { Curarrehue }\end{array}$ & $\begin{array}{l}\text { Cordillera de } \\
\text { los Andes }\end{array}$ & Pintura & Reparo & 1 & $\begin{array}{l}\text { Castelleti } 2007 \\
\text { (con figuras) }\end{array}$ \\
\hline 14 & Huanehue & $\begin{array}{l}\text { Los Ríos, } \\
\text { Panguipulli }\end{array}$ & Precordillera & Grabado & $\begin{array}{l}\text { Cielo } \\
\text { abierto }\end{array}$ & Más de 1 & $\begin{array}{c}\text { Menghin 1959-1960: } \\
81\end{array}$ \\
\hline
\end{tabular}




\begin{tabular}{|c|c|c|c|c|c|c|c|}
\hline $\begin{array}{l}\mathrm{N}^{\circ} \mathrm{EN} \\
\mathrm{FIG} .1\end{array}$ & SITIO & $\begin{array}{l}\text { UBICACIÓN } \\
\text { (región, comuna) }\end{array}$ & $\begin{array}{l}\text { MACROFORMA } \\
\text { LONGITUDINAL }\end{array}$ & TÉCNICA & $\begin{array}{l}\text { TIPO DE } \\
\text { SITIO }\end{array}$ & $\begin{array}{l}\text { № MíNIMO } \\
\text { DE BLOQUES }\end{array}$ & REFERENCIAS \\
\hline 15 & Panguipulli & $\begin{array}{l}\text { Los Ríos, } \\
\text { Panguipulli }\end{array}$ & Precordillera & Grabado & Reparo & 1 & $\begin{array}{c}\text { Van de Maele 1966: } \\
\text { sin páginas } \\
\text { (con figura) } \\
\text { Van de Maele } 1968 \text { : } \\
\text { 22, } 25 \text {, Mapa } 7 \text { y } \\
\text { Mapa } 8\end{array}$ \\
\hline 16 & Lipingue & Los Ríos, Los Lagos & $\begin{array}{l}\text { Depresión } \\
\text { Intermedia }\end{array}$ & Grabado & $?$ & 1 & $\begin{array}{c}\text { Van de Maele 1968: } \\
\text { 22, mapa } 7\end{array}$ \\
\hline 17 & $\begin{array}{l}\text { Cueva de } \\
\text { las Vulvass }\end{array}$ & Los Ríos, La Unión & $\begin{array}{l}\text { Planicies } \\
\text { litorales }\end{array}$ & Grabado & Reparo & 1 & $\begin{array}{l}\text { Adán et al. 2005 } \\
\text { (con figuras) } \\
\text { Adán et al. 2007 } \\
\text { The Nature } \\
\text { Conservancy 2018 } \\
\text { (con figuras) }\end{array}$ \\
\hline 18 & Ojo de Coique & Los Ríos, Futrono & $\begin{array}{l}\text { Depresión } \\
\text { Intermedia }\end{array}$ & Grabado & $\begin{array}{l}\text { Cielo } \\
\text { abierto }\end{array}$ & 1 & $\begin{array}{l}\text { García } 2007 \\
\text { Mera \& Munita } \\
\text { 2008: } 17-18 \\
\text { (con figuras) }\end{array}$ \\
\hline 19 & Cayuruca & Los Ríos, Río Bueno & $\begin{array}{l}\text { Depresión } \\
\text { Intermedia }\end{array}$ & Grabado & $\begin{array}{l}\text { Cielo } \\
\text { abierto }\end{array}$ & 1 & $\begin{array}{l}\text { Van de Maele 1966: } \\
\text { sin páginas } \\
\text { (con figura) } \\
\text { Van de Maele 1968: } \\
\text { 22, mapa } 7 \\
\text { García 2007 } \\
\text { Mera \& Munita } \\
\text { 2008:17-18 } \\
\text { (con figuras) }\end{array}$ \\
\hline 20 & Cachillahue $^{\mathrm{G}}$ & Los Ríos, Río Bueno & $\begin{array}{l}\text { Depresión } \\
\text { Intermedia }\end{array}$ & Grabado & $\begin{array}{l}\text { Cielo } \\
\text { abierto }\end{array}$ & 2 & $\begin{array}{c}\text { Ercilla } \mathrm{N}^{\circ} 1250 \\
\text { del 6-mayo-1959 } \\
\text { (con figura) } \\
\text { Menghin 1964: } \\
\text { 383-384 (con figura) } \\
\text { Fonck 1965: 16-22, } \\
394 \text { (con figura) } \\
\text { Van de Maele 1966: } \\
\text { sin páginas } \\
\text { (con figura) } \\
\text { Van de Maele 1968: } \\
\text { 22, mapa 7 } \\
\text { Niemeyer 1975: } 86 \\
\text { (con figura) } \\
\text { García 2007 } \\
\text { Mera \& Munita } \\
\text { 2008: 17-18 } \\
\text { (con figuras) } \\
\text { Bufoland 2015 } \\
\text { (con figuras) }\end{array}$ \\
\hline 21 & Lago Rupanco $^{\mathrm{H}}$ & $\begin{array}{c}\text { Los Ríos, Entrelagos } \\
\text { o Puerto Octay }\end{array}$ & $\begin{array}{c}\text { Dep. Intermedia } \\
\text { o Precordillera }\end{array}$ & Grabado & $?$ & ND & $\begin{array}{c}\text { Niemeyer \& } \\
\text { Montané 1968: } 438\end{array}$ \\
\hline 22 & Puerto Chico & Los Ríos, Pt. Octay & Dep. Intermedia & Indet. & Reparo & ND & Fonck 1870: 287 \\
\hline 23 & Santa Bárbara 1 & $\begin{array}{c}\text { Los Lagos, Puerto } \\
\text { Varas }\end{array}$ & $\begin{array}{l}\text { Cordillera de } \\
\text { los Andes }\end{array}$ & Pintura & Reparo & 1 & $\begin{array}{l}\text { Dillehay \& Ocampo } \\
\text { 2016: 17, 24-25 } \\
\text { (con figuras) }\end{array}$ \\
\hline 24 & Paredón Luisa & Los Lagos, Cochamó & $\begin{array}{l}\text { Cordillera de } \\
\text { los Andes }\end{array}$ & Pintura & Reparo & 1 & $\begin{array}{c}\text { Moya \& Sierralta } \\
2012\end{array}$ \\
\hline 25 & Torrentoso 01 & Los Lagos, Cochamó & $\begin{array}{c}\text { Cordillera de } \\
\text { los Andes }\end{array}$ & Pintura & Reparo & 1 & $\begin{array}{l}\text { Podestá et al. } 2008 \\
\text { (con figuras) }\end{array}$ \\
\hline 26 & Correntoso 01 & Los Lagos, Cochamó & $\begin{array}{l}\text { Cordillera de } \\
\text { los Andes }\end{array}$ & Pintura & Reparo & 1 & $\begin{array}{l}\text { Podestá et al. } 2008 \\
\text { (con figuras) }\end{array}$ \\
\hline
\end{tabular}




\section{Notas de la Tabla 1}

${ }^{\text {A }}$ Este sitio es descrito por Vergara (1990), aunque su presencia es mencionada en una comunicación personal (Fernando Díaz 1979) ya reportada por Gordon (1980) y por Stehberg (1980). Este último lo refiere bajo los nombres de "Fundo El Roble" y "Las Lavanderas". Seguiremos el nombre dado por su primer descriptor.

${ }^{B}$ Montané (1965-1966) no entrega un nombre propio para este ni para el siguiente sitio. Para evitar confusiones, los hemos denominado como se indica, en consideración de su ubicación y técnica.

${ }^{\mathrm{C}}$ Estimamos que las tres referencias indicadas aluden al mismo hito. Lo parcial de la información entregada nos impide, sin embargo, un juicio definitivo.

D Denominado también "Piedra del Sueco" (Castelleti 2007).

${ }^{\text {E }}$ Estimamos que ha de corresponder a la localidad de Liucura, ubicada en Pucón.
F Denominado también "Colún-4" (Adán et al. 2005).

${ }^{\mathrm{g}}$ Menghin (1964) lo ubica en "Chan-Chan (Provincia de Valdivia)", refiriendo notas de prensa aparecidas en Ercilla (1959) y El Mercurio (1963). La primera solo señala que está ubicado en Río Bueno; no hemos podido consultar directamente la segunda pues, pese a que Menghin ofrece una fecha de publicación (14 de mayo de 1963), dicha nota no se encuentra allí ni en los días cercanos. Luego, Niemeyer y Montané (1968: 437, 442) lo nombran también como Chan Chan, aludiendo a las tres referencias mencionadas arriba. Van de Maele (1966) es el primero que lo trata como Cachillahue. En Río Bueno hay efectivamente una localidad llamada Chan-Chan, cercana a Cachillahue -aunque esta última está más cercana al petroglifo-; sin embargo, esta denominación ha generado una reiterada confusión con el área costera de Chanchán -al norte de Valdivia- y los sitios arqueológicos allí ubicados (p. e., Stehberg 1980).

${ }^{\mathrm{H}}$ Niemeyer y Montané (1968: 438) solo refieren a una información de prensa (El Mercurio 1964). No logramos dar con dicha nota. se trataría de más de uno. La poca cantidad de bloques llama la atención, pues contrasta con la situación de sitios conocidos en el norte semiárido chileno y Chile central, donde se encuentran sitios conformados por un gran número de rocas, como en Cerro Paidahuén (Troncoso et al. 2011), sectores de la reserva Los Cipreses (Niemeyer \& Montané 1968, González 2012) o Guaiquivilo (Niemeyer \& Weisner 1972-1973). Sin embargo, no podemos descartar que el escaso número de soportes reconocidos se deba a la poca investigación arqueológica en la zona, lo que podría derivar en un conocimiento parcial de los sitios arqueológicos.

De todos los sitios registrados, solo siete reportan otras clases de evidencia arqueológica asociada (tabla 2), las que en su mayoría corresponden a material cerámico y lítico. Desconocemos si en los restantes casos esto es consecuencia de su no mención o si significa una real ausencia. En el caso de Cueva de los Catalanes, a partir de las excavaciones arqueológicas allí realizadas, se ha recuperado material cerámico, lítico, arqueofaunístico, botánico y bioantropológico (Menghin 1959-1960, Berdichewsky 1968, Campbell et al. 2017, 2018). Por otra parte, uno de los sitios (Huanehue) se encontraría cercano a un área de cementerio. La presencia de estos materiales arqueológicos en estos siete sitios nos permitiría sugerir, preliminarmente, que el arte rupestre estuvo asociado a diversas actividades, tales como la talla de instrumentos y el consumo de alimentos.

Cabe señalar, además, que la existencia de algunos sitios donde no se pudo identificar material cultural en superficie (p. e., Cerro de la Piedra con Costilla, empla- zado en la cima de un cerro, asociado a un particular afloramiento rocoso y con una vista panorámica hacia la cordillera de la Costa y la de los Andes; o Villucurapinturas, un bloque aislado de 15 metros de altura y único en todo su valle) nos permitiría suponer que la presencia de arte rupestre también pudiera estar dando cuenta de lugares con características no estrictamente domésticas.

Con respecto a la cronología, ninguno de los 26 sitios abordados ha arrojado hasta la fecha evidencia de material diagnósticamente asignable a tiempos precerámicos (12500 AC-150 AC). Por el contrario, a partir de los contextos de los siete sitios ya señalados con evidencia arqueológica asociada, se puede indicar una relación entre el arte rupestre y ocupaciones con presencia de cerámica. Esto podría dar indicios de la cronología tentativa de algunas de estas manifestaciones, vinculándolas a tiempos post-150 AC (Adán et al. 2016, Marsh 2017). Aunque, en último caso, la asociación y contemporaneidad entre el arte rupestre y los restos encontrados casi siempre será discutible. Por otro lado, si bien algunos sitios han sido asociados a grupos cazadores-recolectores (Torrentoso $01 \mathrm{y}$ Correntoso 01), estos serían de adscripción temporal tardía (post-650 AC [1300 AP]) debido a su relación con la Tendencia Abstracta Geométrica Compleja y la Modalidad del Ámbito Lacustre Boscoso (Podestá et al. 2008). Por tales motivos es que se propone tentativamente, para la mayoría de las evidencias rupestres, una cronología enmarcada en, aproximadamente, los últimos 2000 años. 
Tabla 2. Información contextual de los sitios de arte rupestre del sur de Chile. Table2. Contextual information of the rock art sites of southern Chile.

\begin{tabular}{|c|c|c|c|c|c|c|}
\hline $\begin{array}{l}\mathrm{N}^{\circ} \mathrm{EN} \\
\text { FIG. } 1\end{array}$ & SITIO & $\begin{array}{c}\text { EVIDENCIAS } \\
\text { ARQUEOLÓGICAS } \\
\text { ASOCIADAS }\end{array}$ & $\begin{array}{c}\text { INTERVENCIONES } \\
\text { ARQUEOLÓGICAS } \\
\text { (SONDEOS) }\end{array}$ & CRONOLOGÍA & $\begin{array}{c}\text { INTERPRETACIÓN } \\
\text { DEL CONTEXTO }\end{array}$ & REFERENCIAS \\
\hline 5 & Villucura-pinturas & $\begin{array}{l}\text { Lítico, restos } \\
\text { óseos }\end{array}$ & Sí & & $\begin{array}{l}\text { "Escasas } \\
\text { evidencias", } \\
\text { "una posible } \\
\text { ocupación } \\
\text { del lugar por } \\
\text { aborígenes" }\end{array}$ & $\begin{array}{l}\text { Montané } \\
\text { 1965-1966 }\end{array}$ \\
\hline 6 & $\begin{array}{c}\text { Cueva de los } \\
\text { Catalanes }\end{array}$ & $\begin{array}{l}\text { Cerámica, lítico, } \\
\text { osteofauna, } \\
\text { bioantropológica, } \\
\text { arqueobotánica }\end{array}$ & Sí & $\begin{array}{c}637-758 \mathrm{cal} . \mathrm{DC} \\
680-860 \mathrm{cal} . \mathrm{DC} \\
1301-1397 \mathrm{cal} . \mathrm{DC}\end{array}$ & $\begin{array}{l}\text { Sitio ritual y/o } \\
\text { doméstico }\end{array}$ & $\begin{array}{c}\text { Berdichewsky } \\
\text { 1968, } \\
\text { Campbell et al. } \\
2017,2018\end{array}$ \\
\hline 11 & Renahue 2 & Cerámica, lítico & Sí & 1215-1475 DC & $\begin{array}{l}\text { Campamento de } \\
\text { pernocte y talla }\end{array}$ & Castelleti 2007 \\
\hline 17 & Cueva de las Vulvas & $\begin{array}{l}\text { Cerámica, } \\
\text { malacológico }\end{array}$ & No & $\begin{array}{c}\text { Arcaico }(9500 \\
\text { AC-350 DC) } \\
\text { y Alfarero } \\
\text { Temprano } \\
(350-1000 \mathrm{DC})^{\mathrm{B}}\end{array}$ & $\begin{array}{l}\text { Espacio de uso } \\
\text { doméstico, } \\
\text { refugio, área } \\
\text { de trabajos } \\
\text { específicos; } \\
\text { probablemente } \\
\text { de uso estacional }\end{array}$ & Adán et al. 2005 \\
\hline 18 & Ojo de Coique & Cerámica, lítico & No & & Sitio habitacional & $\begin{array}{c}\text { Mera \& Munita } \\
2008\end{array}$ \\
\hline 20 & Cachillahue & Cerámica, lítico & Sí & $\begin{array}{l}\text { Alfarero Tardío } \\
\text { (1000-1550 DC) }\end{array}$ & Sitio habitacional & $\begin{array}{c}\text { Van de Maele } \\
1966, \\
\text { Mera \& Munita } \\
2008\end{array}$ \\
\hline 23 & Santa Bárbara 1 & $\begin{array}{l}\text { Cerámica, } \\
\text { osteofauna }\end{array}$ & Sí & $\begin{array}{c}1280 \pm 40 \text { no cal. } \\
\text { DC"C }\end{array}$ & $\begin{array}{l}\text { Asentamiento } \\
\text { permanente o } \\
\text { semipermanente }\end{array}$ & $\begin{array}{c}\text { Dillehay \& } \\
\text { Ocampo } 2016\end{array}$ \\
\hline
\end{tabular}

\section{Notas de la Tabla 2}

${ }^{\mathrm{A}}$ En el caso de Cueva de los Catalanes, los fechados son ${ }^{14} \mathrm{C}$ (rango calibrado con $2 \sigma$ ); en el de Renahue 2 es termoluminiscencia (rango con $2 \sigma$ ).
${ }^{\text {B }}$ Sin embargo, Adán et al. (2005: 10) señalan que "Si bien no se recuperaron materiales correspondientes al Período Arcaico, por los antecedentes conocidos para la costa y las potencialidades de este asentamiento se puede plantear de manera hipotética una ocupación en momentos precerámicos".

${ }^{\mathrm{C}}$ Así es referida por Dillehay y Ocampo (2016: 26).
En síntesis, a partir de los resultados presentados, se destaca que los sitios de arte rupestre del sur de Chile se caracterizan por su baja densidad espacial y por estar ampliamente distribuidos a lo largo del territorio. Estos se ubican en una variedad de ambientes y sectores altitudinales, encontrándose a cielo abierto o en repa- ros, estando conformados por conjuntos de bloques o bien aislados, y relacionándose a distintas actividades, tanto domésticas como no domésticas. Respecto de su temporalidad, estas manifestaciones se asociarían a las comunidades alfareras de la región. 
Tabla 3. Características tecnológicas de los sitios de arte rupestre del sur de Chile (Puerto Chico no cuenta con información respecto de su técnica). Table 3. Technological characteristics of the rock art sites of southern Chile (no information about their technique is available in Puerto Chico).

\begin{tabular}{|c|c|c|c|c|}
\hline \multirow{2}{*}{$\begin{array}{c}N^{\circ} \text { EN LA } \\
\text { FIG. } 1\end{array}$} & \multirow[t]{2}{*}{ SITIO } & \multirow{2}{*}{$\begin{array}{c}\text { PINTURAS } \\
\text { COLOR DEL TRAZO }\end{array}$} & \multicolumn{2}{|c|}{ GRABADO } \\
\hline & & & SURCO PROFUNDO & SURCO SUPERFICIAL \\
\hline 1 & Los Peñascos & & Indeterminado & Indeterminado \\
\hline 2 & Paso Hondo & & Sí & Indeterminado \\
\hline 3 & Cerro de la Piedra con Costilla & & Sí & No \\
\hline 4 & Villucura-petroglifo & & Indeterminado & Indeterminado \\
\hline 5 & Villucura-pinturas & Blanco & & \\
\hline 6 & Cueva de los Catalanes & & Sí & Sí \\
\hline 7 & Purén-Pangueco & & Indeterminado & Indeterminado \\
\hline 8 & Maloñehue 1 & & Indeterminado & Indeterminado \\
\hline 9 & Petroglifos del Llaima & & Indeterminado & Indeterminado \\
\hline 10 & Hueñivales & & Indeterminado & Indeterminado \\
\hline 11 & Renahue 2 & Rojo & & \\
\hline 12 & Liucura & Indeterminado & & \\
\hline 13 & Pocolpén & Rojo & & \\
\hline 14 & Huanehue & & Indeterminado & Indeterminado \\
\hline 15 & Panguipulli & & Indeterminado & Indeterminado \\
\hline 16 & Lipingue & & Indeterminado & Indeterminado \\
\hline 17 & Cueva de las Vulvas & & Sí & Sí \\
\hline 18 & Ojo de Coique & & Sí & No \\
\hline 19 & Cayuruca & & Sí & Indeterminado \\
\hline 20 & Cachillahue & & Sí & Indeterminado \\
\hline 21 & Lago Rupanco & & Indeterminado & Indeterminado \\
\hline 23 & Santa Bárbara 1 & Rojo & & \\
\hline 24 & Paredón Luisa & Rojo & & \\
\hline 25 & Torrentoso 01 & Rojo & & \\
\hline 26 & Correntoso 01 & Rojo & & \\
\hline
\end{tabular}

\section{Aspectos tecnológicos e iconográficos del arte rupestre}

Es importante hacer hincapié en que, debido a la diversidad de fuentes consultadas y la disímil calidad de la información disponible en estas, no contamos con la claridad requerida respecto de los aspectos tecnológicos e iconográficos. No obstante, casi todas las fuentes hacen mención a las técnicas empleadas en la manufactura del arte rupestre, señalando que estas corresponden a pinturas o grabados. Cabe destacar que todas las pinturas se encuentran en reparos rocosos, lo que puede estar sesgado debido a las favorables características de preservación que tienen estos ambientes, al aislarlas de agentes de deterioro como la radiación solar y el agua. Los grabados, en tanto, se hallan a cielo abierto y también en reparos rocosos. Con relación a la distribución de los tipos de técnicas, 17 sitios presentan grabados, ocho son pinturas, y solo para uno no se la detalla (fig. 1); en ninguno de los sitios se identificaron grabados y pinturas a la vez. Los sitios de grabados se ubican a lo largo de todo el territorio considerado y en todas las macroformas longitudinales; en cambio, las pinturas solo en sectores precordilleranos y cordilleranos andinos.

De los ocho sitios con pinturas, en seis los motivos se presentan en color rojo, en uno en color blanco, y en uno los colores no son descritos (tabla 3). Las evidencias 

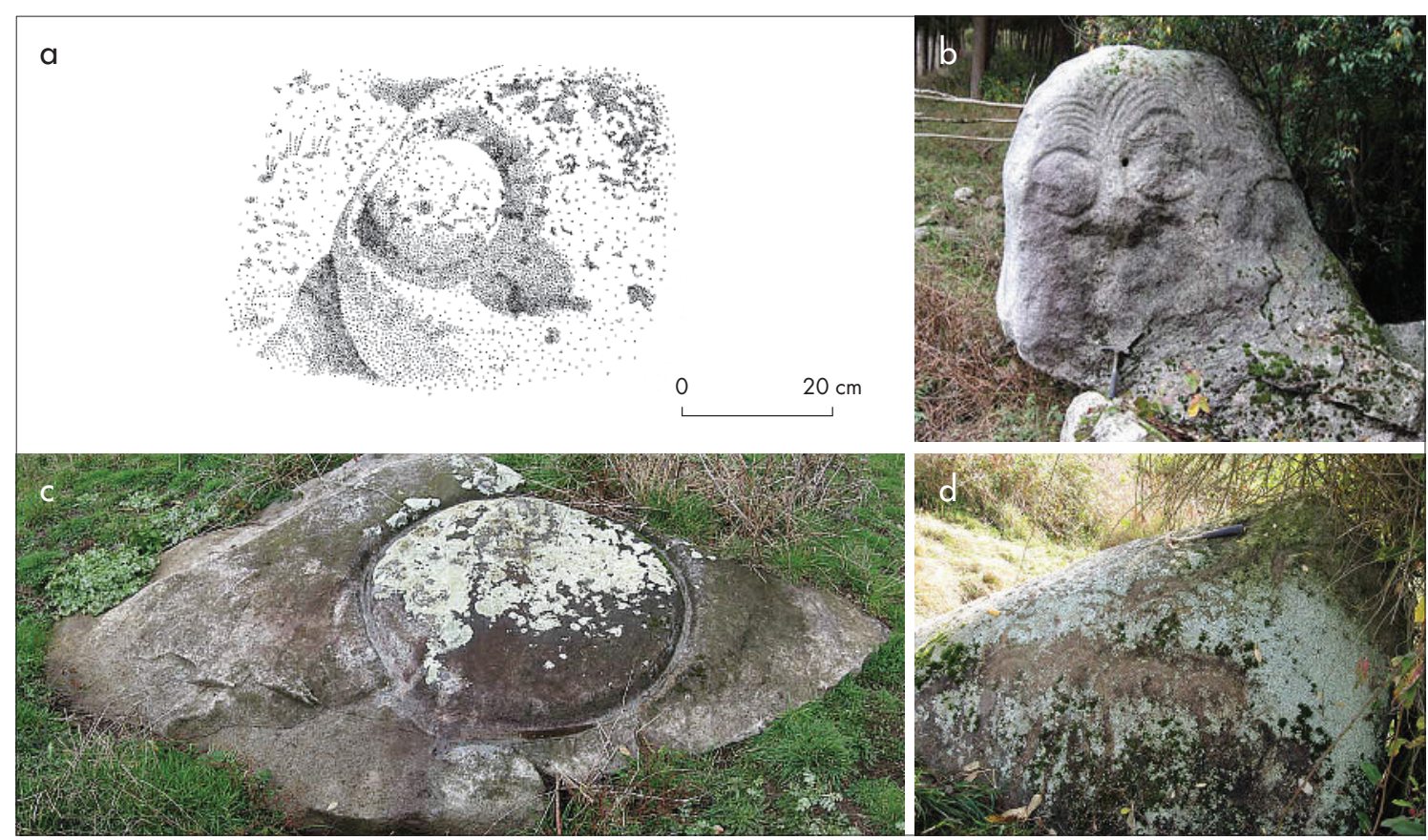

Figura 2. Ejemplos de grabados de surco profundo: a) Paso Hondo (Vergara 1991); b) Cachillahue (Mera \& Munita 2008); c) Ojo de Coique (Mera \& Munita 2008); d) Cayuruca (Mera \& Munita 2008). Ver también figura 4c-d (Cerro de la Piedra con Costilla). Imágenes b, c y d no cuentan con escala en los textos originales. Figure 2. Examples of deep-line engraving: $\boldsymbol{a})$ Paso Hondo (Vergara 1991); $\boldsymbol{b}$ ) Cachillahue (Mera \& Munita 2008); c) Ojo de Coique (Mera \& Munita 2008); d) Cayuruca (Mera \& Munita 2008). See figure 4c-d also (Cerro de la Piedra con Costilla). The scale of images $b, c$, and $d$ is not specified in the original texts.

de estos distintos colores en el arte rupestre implican la existencia de conocimientos de aprovisionamiento, procesamiento y aplicación de diversas materias pigmentarias.

Con respecto a los grabados (tabla 3), llama la atención que en los trabajos que cuentan con fotografías o dibujos se observa que, en la mayoría, estos presentan altas continuidades de surco que podrían relacionarse con técnicas de raspado (Álvarez \& Fiore 1995). Solo Villucura-petroglifo se aleja de esta situación, pues se observan oquedades, o bien, un diseño realizado a partir de surcos muy discontinuos. Por otra parte, en al menos siete sitios se distinguen grabados de surco profundo (Vergara \& Troncoso 2015) (fig. 2). Tres de estos sitios se concentran en el área de Lago Ranco-Río Bueno (Cayuruca, Ojo de Coique, Cachillahue), mientras que otros dos, en las cercanías de Concepción (Cerro de la Piedra con Costilla, Paso Hondo) (fig. 1). Los otros dos sitios (Cueva de los Catalanes, Cueva de las Vulvas) difieren de los anteriores ya que, si bien presentan grabados de surco profundo, estos han sido elaborados sobre una roca muy blanda, como la arenisca. $\mathrm{Al}$ respecto, cabe señalar que lo anterior presentaría menor dificultad de manufactura en comparación con rocas de mayor dureza, como el granito.

Respecto del número de motivos por sitio, el análisis del registro bibliográfico revela que la cantidad es muy variada entre los sitios que cuentan con esta información (tabla 4). Ello se debe a que la mayoría presenta una baja cantidad de motivos (entre uno y cinco), mientras que otros evidencian un gran número. Entre ellos destaca Cueva de los Catalanes y Petroglifos del Llaima, con 105 y 92 motivos, respectivamente.

Se han registrado tanto motivos figurativos como no figurativos. En todos los sitios (tabla 4) priman los diseños no figurativos o abstractos, conformados a base de líneas, círculos, cuadriláteros, etc. Tales diseños presentan amplia variabilidad, sin que sea posible hasta hoy definir estilos a partir de las características iconográficas.

En cuanto a los motivos figurativos, solamente en dos sitios se registran antropomorfos: Villucurapinturas y Maloñehue 1 (fig. 3 y tabla 4), es decir, diseños que presentan figuras humanas de cuerpo 
Tabla 4. Cantidad y tipos de diseños en los sitios de arte rupestre del sur de Chile (Liucura, Lipingue, Lago Rupanco y Puerto Chico no cuentan con información respecto de sus motivos). Table 4. Number and types of designs at the rock art sites of southern Chile (no information is available regarding the motifs of Liucura, Lipingue, Lago Rupanco, and Puerto Chico).

\begin{tabular}{|c|c|c|c|c|c|}
\hline \multirow{2}{*}{$\begin{array}{c}N^{\circ} \text { EN LA } \\
\text { FIG. } 1\end{array}$} & \multirow[t]{2}{*}{ SITIO } & \multirow{2}{*}{$\begin{array}{l}\text { NÚMERO DE } \\
\text { MOTIVOS }\end{array}$} & \multirow[t]{2}{*}{ NO FIGURATIVOS } & \multicolumn{2}{|c|}{ FIGURATIVOS } \\
\hline & & & & ANTROPOMORFOS & ROSTROS \\
\hline 1 & Los Peñascos & 5 & $\mathrm{x}$ & & \\
\hline 2 & Paso Hondo & Indeterminado & $\mathrm{x}$ & & \\
\hline 3 & Cerro de la Piedra con Costilla & 10 & $\mathrm{x}$ & & $\mathrm{x}$ \\
\hline 4 & Villucura-petroglifo & 1 & $\mathrm{x}$ & & \\
\hline 5 & Villucura-pinturas & 26 & $\mathrm{x}$ & $\mathrm{x}$ & \\
\hline 6 & Cueva de los Catalanes & 105 & $\mathrm{x}$ & & \\
\hline 7 & Purén-Pangueco & 6 & $\mathrm{x}$ & & \\
\hline 8 & Maloñehue 1 & 18 & $\mathrm{x}$ & $\mathrm{x}$ & \\
\hline 9 & Petroglifos del Llaima & 92 & $\mathrm{x}$ & & \\
\hline 10 & Hueñivales & 3 & $\mathrm{x}$ & & \\
\hline 11 & Renahue 2 & Indeterminado & $\mathrm{x}$ & & \\
\hline 12 & Liucura & Indeterminado & & & \\
\hline 13 & Pocolpén & 3 & $\mathrm{x}$ & & \\
\hline 14 & Huenahue & Indeterminado & $\mathrm{x}$ & & \\
\hline 15 & Panguipulli & 1 & $\mathrm{x}$ & & \\
\hline 16 & Lipingue & Indeterminado & & & \\
\hline 17 & Cueva de las Vulvas & Indeterminado & $\mathrm{x}$ & & \\
\hline 18 & Ojo de Coique & 1 & $\mathrm{x}$ & & \\
\hline 19 & Cayuruca & 1 & $\mathrm{x}$ & & \\
\hline 20 & Cachillahue & 10 & $\mathrm{x}$ & & \\
\hline 21 & Lago Rupanco & Indeterminado & & & \\
\hline 23 & Santa Bárbara 1 & 2 & $\mathrm{x}$ & & \\
\hline 24 & Paredón Luisa & 4 & $\mathrm{x}$ & & \\
\hline 25 & Torrentoso 01 & 32 & $\mathrm{x}$ & & \\
\hline 26 & Correntoso 01 & 3 & $\mathrm{x}$ & & \\
\hline
\end{tabular}

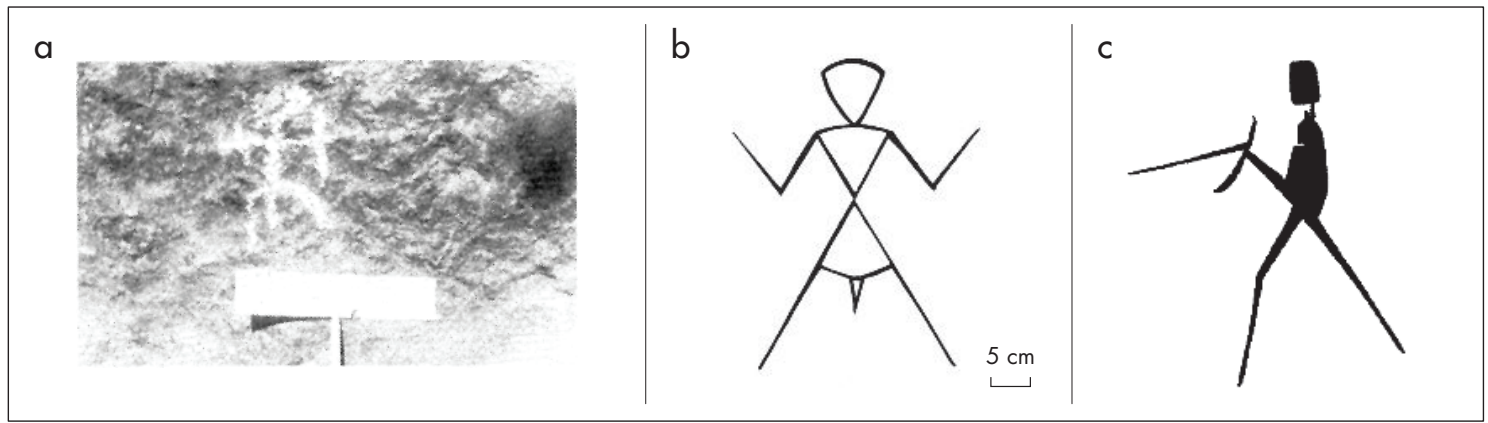

Figura 3. Diseños antropomorfos del sur de Chile: a) Villucura-pinturas (Montané 1965-1966); b-c) Maloñehue 1 (Inostroza et al. 1984, 1983, respectivamente). Las imágenes a y c no cuentan con escala en los textos originales; en b la escala es $5 \mathrm{~cm}$. Figure 3 . Anthropomorphic designs of southern Chile: a) Villucura-paintings (Montané 1965-1966); b-c) Maloñehue 1 (Inostroza et al. 1984, 1983, respectively). The scale of images $\boldsymbol{a}$ and $\boldsymbol{c}$ is not specified in the original texts; the scale in $\boldsymbol{b}$ is $5 \mathrm{~cm}$. 


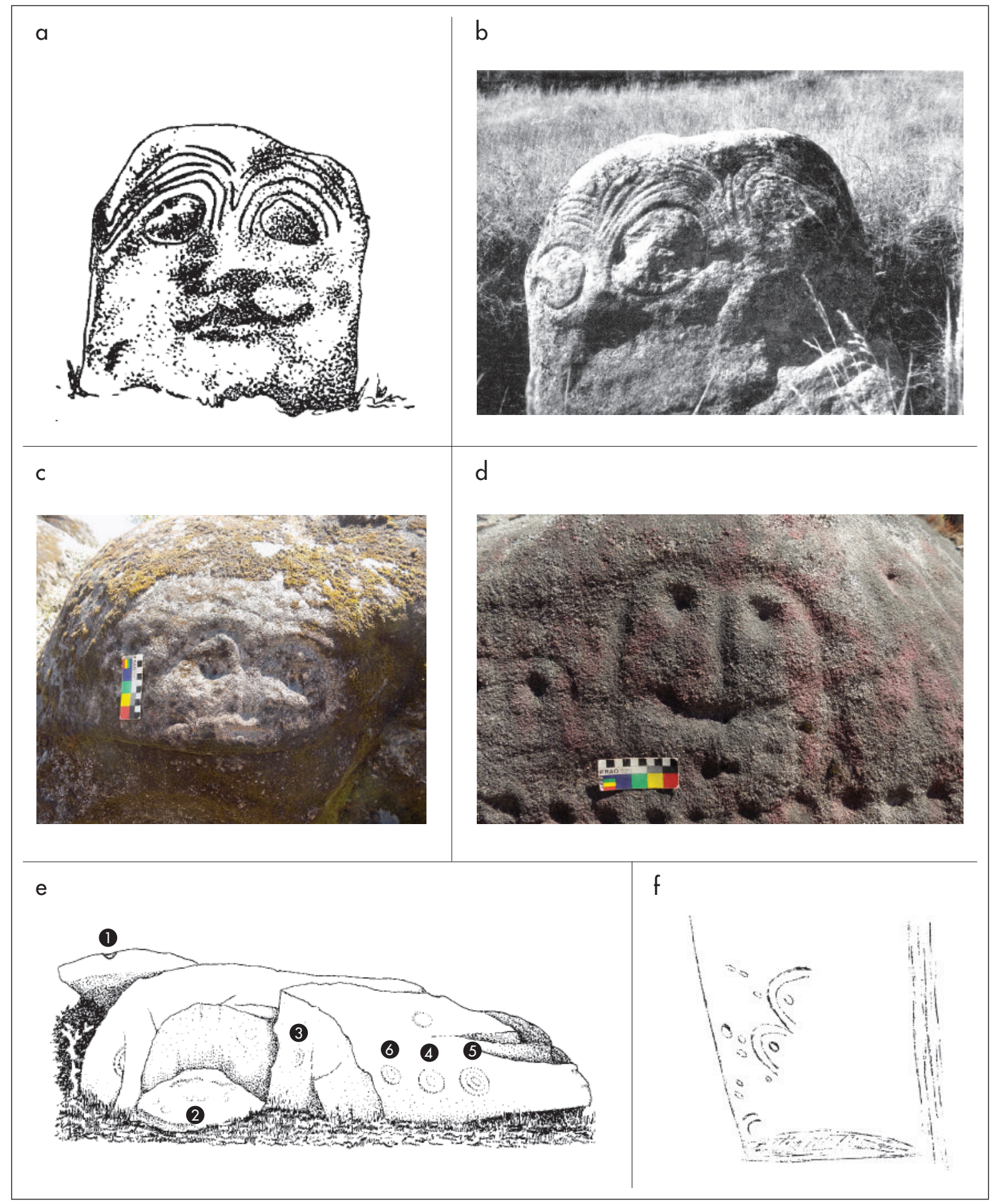

Figura 4. Diseños interpretados distintamente como rostros del sur de Chile: a y b) Cachillahue (Fonck 1965, Mostny \& Niemeyer 1983, respectivamente); c y d) Cerro de la Piedra con Costilla (Fotografías: R. Gutiérrez y F. Moya); e) Los Peñascos (Vergara 1990);f) Cayuruca (Van de Maele 1966). Solo c y d los interpretamos como rostros, e y f son posibles rostros (e corresponde al número 2 indicado en el original). Las imágenes a, b, e y f no cuentan con escala en los textos originales. Figure 4. Designs variously interpreted as faces of the south of Chile: $\boldsymbol{a}$ and $\boldsymbol{b}$ ) Cachillahue (Fonck 1965, Mostny \& Niemeyer 1983, respectively); $\boldsymbol{c}$ and $\boldsymbol{d}$ ) Cerro de la Piedra con Costilla (Photographs by R. Gutiérrez and F. Moya); e) Los Peñascos (Vergara 1990); f) Cayuruca (Van de Maele 1966). We have interpreted only c and d as faces, $\boldsymbol{e}$ and $f$ may be faces (in e corresponds to number 2 in the original). The scale of images $\boldsymbol{a}, \boldsymbol{b}, \boldsymbol{e}$, and $\boldsymbol{f}$ is not specified in the original texts. 
completo. Estos difieren entre sí, pues en el primero hay motivos pintados de cuerpo lineal, mientras que en el segundo son grabados de cuerpo conformado por figuras geométricas.

Cabe señalar que en Cerro de la Piedra con Costilla se identificaron diseños que podrían corresponder a rostros y que se asemejan al motivo de ceja-nariz continua de la cerámica modelada del Complejo Pitrén (fig. 4). En este sentido, las fuentes consultadas no permiten identificar fuera de duda la presencia de otros motivos, como zoomorfos y pisadas de animales, los cuales sí forman parte de estilos de arte rupestre aledaños al área de estudio.

\section{DISCUSIÓN}

La revisión bibliográfica y los puntuales registros realizados en terreno dan cuenta de un repertorio iconográfico heterogéneo y primordialmente no figurativo, en el cual se utilizaron tanto técnicas de grabado como pintura. Dicho repertorio se ubica en sitios con emplazamientos disímiles y que, seguramente, presentaron funcionalidades diferentes. A pesar de esta variabilidad, hay algunos aspectos que surgen tanto de nuestra revisión como de las reflexiones previas de otros investigadores. Es lo que abordaremos a continuación.

\section{$¿$ El estilo Guaiquivilo tiene un alcance regional?}

La propuesta de Niemeyer y Weisner (1972-1973) respecto de lo que ellos definieron como estilo Guaiquivilo ha sido un "constructo rupestrológico" importante para entender el arte rupestre del sur de Chile (Gordon 1980, Inostroza et al. 1983, Castelleti 2007). Ello se debe a que aparece como el referente arqueológico estructurado más cercano a dicha zona y, por lo tanto, pudiera ser útil para articular el registro del sur de Chile con el de otras zonas. Sin embargo, es necesario notar que media una distancia de $150 \mathrm{~km}$-en línea recta-entre la acotada área donde se manifiesta dicho estilo y el sitio de arte rupestre del sur de Chile más cercano a aquella (Los Peñascos) (fig. 1).

De este modo, nuestra revisión muestra que, a la fecha, los motivos, técnicas y patrón de emplazamiento -y su combinación- que singularizan el estilo Guaiquivilo se circunscriben al sector cordillerano de la cuenca del río Maule (Diario Ilustrado 1958, Mueller 1958, Vea 1958,
Niemeyer \& Weisner 1972-1973, Vergara 1972-1973, Niemeyer 1975, 1979, Lara 2002, Ilustre Municipalidad de Colbún 2003, Morales et al. 2015, Reyes 2016). Asimismo, las características principales que definen al estilo Guaiquivilo, como su emplazamiento en espacios cordilleranos de uso estival, su circunscripción en concentraciones densas de grabados sobre grandes afloramientos rocosos, la mayoría a nivel de superficie, y la presencia de diseños característicos, como es el caso de la impronta de pie humano, entre otros (Niemeyer \& Weisner 1972-73), serían elementos no compartidos por los sitios registrados en el sur de Chile.

En este sentido, este estilo no se manifestaría tampoco en los sitios de arte rupestre del valle central más cercanos a dicha área, como son Cerro Quiñe (Sanguinetti 1970, Morales et al. 2015) y Fundo San Manuel (Fontecilla 1936, Montandon 1958, Morales et al. 2015), ni en los sectores precordilleranos y cordilleranos ubicados más al sur (fig. 1). Por el contrario, la similitud del estilo Guaiquivilo con el arte rupestre del norte de Neuquén, Argentina, es evidente. Este aspecto ha sido señalado ya en trabajos como el de Schobinger (1957) y reiterado por sucesivos investigadores como Niemeyer y Weisner (1972-1973), Fernández (1974-1976, 2000 [1979]) y Romero (Romero \& Re 2014, Romero 2016). ${ }^{4}$

Por otra parte, hacemos eco de la reflexión de Troncoso (2002: 25), al decir que:

\footnotetext{
la complejización teórica del concepto de estilo implica que lo que se agrupa bajo el nombre de Guaiquivilo no responde a los criterios actuales para asociar un conjunto de representaciones a un estilo en sentido estricto. Por el contrario, Guaiquivilo hace referencia a una serie de grabados rupestres identificados en una determinada área geográfica, desconociéndose si todas las figuras se relacionan con una misma formación socio-cultural.
}

Nuestra reflexión es similar a la de Troncoso. Hasta que el estilo Guaiquivilo no sea adecuadamente investigado, será difícil decir algo concluyente e incluso utilizarlo como referente para abordar otras manifestaciones rupestres. Esto requeriría definir su cronología, sus asociaciones materiales y ubicarlo en un contexto arqueológico regional. De hecho, esta situación de desconocimiento y descontextualización es extensible a los sitios de Cerro Quiñe y Fundo San Manuel.

Finalmente, la exclusión que hemos hecho de los sitios de arte rupestre de la región del Maule de la síntesis sobre aquel del sur de Chile, se origina a partir 
de las características diferenciales que fueron surgiendo durante el procesamiento de la información recabada. Estas, como se ha señalado, aluden principalmente al emplazamiento y densidad de las manifestaciones rupestres, como también al repertorio de motivos plasmados.

\section{¿Existe el "estilo de rostros" del área araucana?}

Niemeyer y Montané (1968) propusieron originalmente este estilo, y luego Mostny y Niemeyer (1983) elaboraron más explícitamente esta propuesta. A su vez, Castelleti (2007: 58) y Pérez y Salaberry (2014: 82), citando a estos últimos, lo llamarán "Estilo de la Araucanía".

Este estilo tiene sus referentes de definición en Cachillahue y Cerro de la Piedra con Costilla. Sin embargo, a partir de la información recopilada por nosotros, la intención de representar rostros no es evidente en el caso del primero (fig. 4a-b). En este lugar, el motivo representado corresponde a tres círculos con líneas curvas continuas perimetrales sobre estos, de modo que no es fácilmente interpretable como un par de ojos con cejas. Sin embargo, esta pareciera ser la situación en el caso de Cerro de la Piedra con Costilla (fig. 4c y d), al que pudieran sumarse, respetando la definición dada para este estilo, Los Peñascos y Cayuruca (fig. 4 e y f), aunque la información (dibujos y descripción) con que contamos hasta hoy es muy parcial.

Por lo tanto, estimamos que, con la evidencia actual, la existencia de este estilo queda en entredicho, pues se observa una mayor variabilidad que la sugerida en un primer momento. Si bien se visualizan elementos comunes, como círculos y líneas curvas, su combinación, morfología y estructura difieren entre sí. No obstante, la tendencia humana a representar rostros de una manera esquemática (cejas-nariz continuas y ojos) parece reflejarse en distintos puntos del sur de Chile, como también en diferentes soportes materiales (cerámica, piedra). Con todo, esto no sería constitutivo de un estilo de arte rupestre de alcance regional, pues su presencia se manifestaría solo en algunos sitios de arte rupestre y se mostraría diversa entre sí.

\section{¿Son las "vulvas" un motivo común al sur de Chile?}

Oyarzún (1910) plantea en su trabajo fundacional que los motivos representados en los dos bloques de los
Petroglifos del Llaima corresponderían al diseño de vulvas. Este mismo motivo es referido nuevamente por Berdichewsky (1968) para el caso de Cueva de los Catalanes. Sin embargo, como señala Gordon (1980), aludiendo al arte rupestre de distintas épocas y lugares del mundo, "A través de la bibliografía, los símbolos de forma elíptica con eje longitudinal [...] y los círculos con punto central $[\ldots]$ generalmente se interpretan como 'vulvas"'. En particular, su interpretación de aquellos del sur de Chile y Neuquén (Argentina), es "que el signo de 'vulva' es la representación simbólica del guanaco" (Gordon 1980: 70-71).

Dicho motivo, aunque con algunas variaciones, lo encontramos efectivamente en Cueva de los Catalanes y también en Purén-Pangueco, Maloñehue 1, Cueva de las Vulvas (fig. 5c-f) y Los Peñascos (fig. 4e). Se lo observa solo en técnica de grabado y presenta una distribución espacial acotada, entre los ríos Itata-Núnle y Toltén, con excepción de Cueva de las Vulvas y desde la costa a la cordillera andina.

No contamos con evidencia para plantear que se trate efectivamente de una representación de los órganos sexuales femeninos y bien podría corresponder a un motivo abstracto. Podríamos estar en este caso ante un elemento común en parte del sur de Chile. Con relación a Cueva de los Catalanes, el registro realizado por nosotros dio cuenta de la posible presencia de este elemento, pero con un alto grado de variabilidad en su construcción, pudiéndose tratar de diseños distintos. De hecho, el único elemento común que se identificó en aquellos diseños que podrían aludir a vulvas fue la presencia de un trazo lineal inscrito en una figura geométrica como un semicírculo, un rombo o dos trazos paralelos (fig. 5). Consideramos que la lectura de la evidencia relevada y publicada, bien pudiera estar afectada por el afán arqueológico de hallar este motivo -el de la vulva-, y ello en desmedro de otros motivos posiblemente también transversales.

\section{¿Qué hay de los surcos profundos?}

Como señalamos en el apartado referido a tecnología, un aspecto relativamente recurrente del arte rupestre del sur de Chile sería la técnica de surcos profundos. Esta fue positivamente identificada por nosotros en siete sitios, manifestándose mayoritariamente sobre rocas graníticas. Esto se observa en Paso Hondo, Cerro de la Piedra con Costilla, Cachillahue, Ojo de Coique y Cayuruca, en 


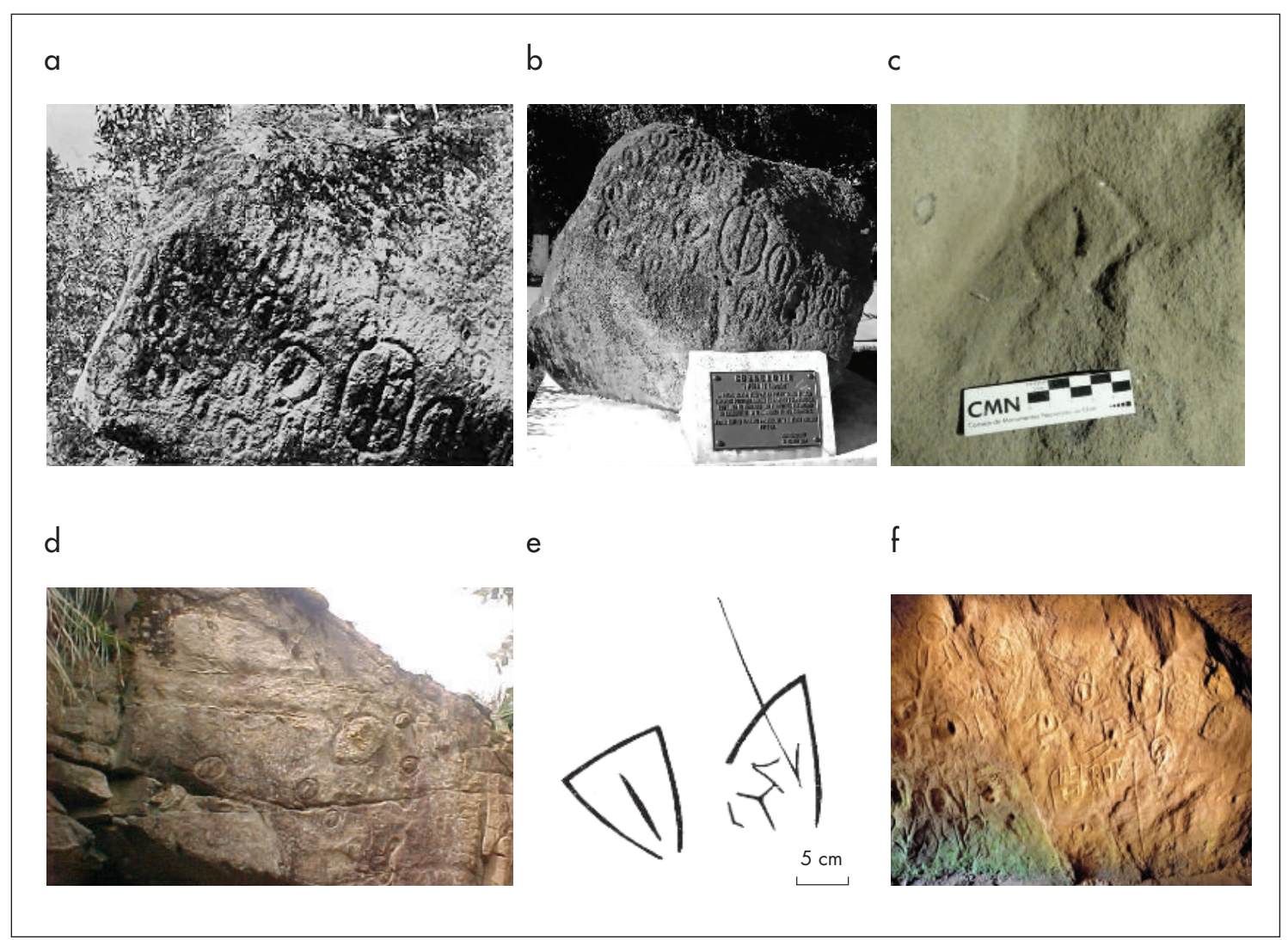

Figura 5. Diseños de "vulvas": a y b) Petroglifos del Llaima (Oyarzún 1910, Piedra de Reunión 2011, respectivamente); c) Cueva de los Catalanes (Gutiérrez 2016); d) Purén-Pangueco (Lara 2014); e) Maloñehue 1 (Inostroza et al. 1984), f) Cueva de las Vulvas (The Nature Conservancy 2018). Ver también aquí figura 4e, números 3 al 6 indicados en el original. Imágenes a, b, c, d y f no cuentan con escala en los textos originales; en e la escala es $5 \mathrm{~cm}$. Figure 5. 'Vulva' designs: $\boldsymbol{a}$ and b) Llaima petroglyphs (Oyarzún 1910, Piedra de Reunión 2011, repectively); c) Catalanes Cave (Gutiérrez 2016); d) Purén-Pangueco (Lara 2014); e) Maloñehue 1 (Inostroza et al. 1984), f) Vulvas Cave (The Nature Conservancy 2018). Also see figure 4e, numbers 3 to 6 noted in the original. The scale of images $a, b, c, d$, and $f$ is not specified in the original texts; the scale in e is $5 \mathrm{~cm}$.

la forma de círculos o círculos acompañados de líneas curvas (por eso algunas veces han sido interpretados como ojos, y desde allí, como rostros) (fig. 2, fig. 4bd). Aunque no esté claro el motivo representado, cabe destacar que, a nivel tecnológico, la creación de estos grabados debió requerir una importante inversión de tiempo debido a la dureza de su soporte. Por lo tanto, se puede plantear que tales grabados serían el resultado de una reiterativa práctica de grabar sobre la misma figura (Vergara \& Troncoso 2015). Esto se hace particularmente evidente en Ojo de Coique, donde el surco tiene más de $5 \mathrm{~cm}$ de profundidad.

Aunque es difícil definir hoy un estilo a partir de la información disponible, sí podemos afirmar que la creación de este tipo de petroglifos requirió prácticas tecnológicas similares. Esto los diferencia de los otros dos sitios con surcos profundos (Cueva de los Catalanes y Cueva de las Vulvas), cuyos grabados fueron manufacturados sobre rocas blandas, además de presentar surcos superficiales (fig. 5c y f) y, obviamente, también de los sitios con pinturas.

Su distribución estaría entre los ríos Itata-Ñuble y Bueno y, con mayor precisión, en dos sectores diferenciados: entre los ríos Itata-Ñuble y Biobío en la cordillera de la Costa y Depresión Intermedia, y en el área de Lago Ranco-Río Bueno en la Depresión Intermedia (fig. 1). Por lo tanto, en cuanto a su distribución, se sobrepondría parcialmente al motivo de las vulvas. 


\section{Arte rupestre, piedras santas y piedras tacitas}

Un elemento presente en algunos sitios de arte rupestre del sur de Chile son las oquedades. Tal es el caso de Villucura-petroglifo, donde dichas oquedades constituyen el único motivo que fue relevado. A su vez, Cerro de la Piedra con Costilla presenta en sus bloques diseños conformados por horadaciones. En tanto, en Cueva de los Catalanes y Cueva de las Vulvas las oquedades se encuentran con distinta profundidad dispersas en las paredes; tienen tamaños variables, desde $1 \mathrm{a} 10 \mathrm{~cm}$ de diámetro, con profundidades desde los 0,2 a $10 \mathrm{~cm}$ y con forma tubular o semiesférica.

Las características de estas oquedades y del emplazamiento de los sitios que las presentan hacen recordar dos manifestaciones pétreas: las piedras tacitas y las piedras santas. Por una parte, una piedra tacita refiere a horadaciones presentes en un bloque en su plano horizontal y su función sería la de contener algo. Por otra, desde la cosmovisión mapuche, una piedra santa corresponde a una roca imbuida de poder, ubicada generalmente en caminos y a la que se le realizan rogativas o pagos que se depositan en o sobre ella (Schindler \& Schindler-Yáñez 2006, Menard 2017). ${ }^{5}$

Según estas descripciones, las dos manifestaciones (piedra tacita y piedra santa) podrían ser perfectamente compatibles en un mismo hito. Tal parece ser el caso de la piedra tacita de Guanecura, referida por Calvo (1968) como una piedra ritual. Más complejo es el caso de la "Piedra de los Rastros" (Neuquén, Argentina) descrita por Fernández (1974-1976), la que, además de presentar grabados rupestres (de tridígitos y pisadas de felinos, entre otros motivos), cuenta con una serie de excavaciones hemiferoides de tamaño pequeño y muy pequeño en las cuales los viajeros dejan ofrendas. Finalmente, está la piedra santa de Retricura (Oyarzún 1924, Verniory 2001, Schindler \& Schindler-Yáñez 2006), un bloque rocoso de $20 \mathrm{~m}$ de altura, a la cual los viajeros que se dirigían -y se dirigen- a Lonquimay y al cruce de la cordillera de los Andes realizaban rogativas. Esta piedra cuenta con oquedades en su pared suroeste, donde pueden dejarse ofrendas y pagos (fig. 6).

Respecto de la piedra santa de Retricura - visitada por nosotros- es relevante para nuestros fines señalar que dicha pared genera un pequeño alero, inmediatamente accesible desde el camino, además de ser la única superficie lisa que presenta el bloque. Esto último ha generado que dicha pared haya sido y sea "vandalizada" con diversos mensajes, principalmente religiosos. Estas características son, en parte, compartidas con Villucurapinturas, pues este último corresponde a un bloque aislado de alrededor de $15 \mathrm{~m}$ de altura -siendo el único de su tipo en el valle del río Duqueco y por ello un hito a nivel local-, y donde las pinturas rupestres se ubican en la única pared lisa disponible, la que también forma un alero. Por tanto, no sorprendería que en el pasado Villucura-pinturas hubiese sido también una piedra santa, ni tampoco que bajo las capas de pintura moderna de la piedra santa de Retricura hayan existido también pinturas rupestres indígenas (fig. 6).

A partir de lo dicho, se abre la posibilidad de que las oquedades halladas en las paredes de Cueva de las Vulvas y Cueva de los Catalanes hayan servido para el depósito de ofrendas y que dichos espacios correspondiesen a áreas rituales o ritualizadas. En este sentido, las cuevas pueden aludir a lo numinoso en la cosmovisión mapuche (Adán 2014: 278-295), siendo una de sus acepciones la de renü que, según Augusta (1916a: 196, 1916b: 94) corresponde a cueva subterránea en que se forman los hechiceros o donde celebran sus conciliábulos. Del mismo modo, y sin ser excluyente con lo anterior, las manifestaciones pétreas referidas (piedra tacita, piedra santa y arte rupestre) pudieron haber constituido landmarks (Golledge 2003), pues permiten identificar ubicaciones en el territorio, constituyendo conceptos organizadores de los mapas mentales y facilitando el trazado y transmisión de información sobre rutas.

\section{CONCLUSIONES}

La revisión presentada en este trabajo nos permitió generar una evaluación inicial y exploratoria sobre el arte rupestre del sur de Chile. Estimamos que esta síntesis es un paso necesario antes de proceder con otros trabajos que apunten a abordar sitios específicos o que busquen contextualizar culturalmente estas manifestaciones. Del mismo modo, el trabajo permitió relevar casos cuya búsqueda y confirmación podrían convertirse en temas de futura investigación.

El registro de arte rupestre en el sur de Chile muestra ser más abundante y variado de lo que generalmente se plantea. Además, difiere en gran medida de lo que se conoce para sus zonas aledañas. En este sentido, por un lado, las representaciones asociadas con el estilo 


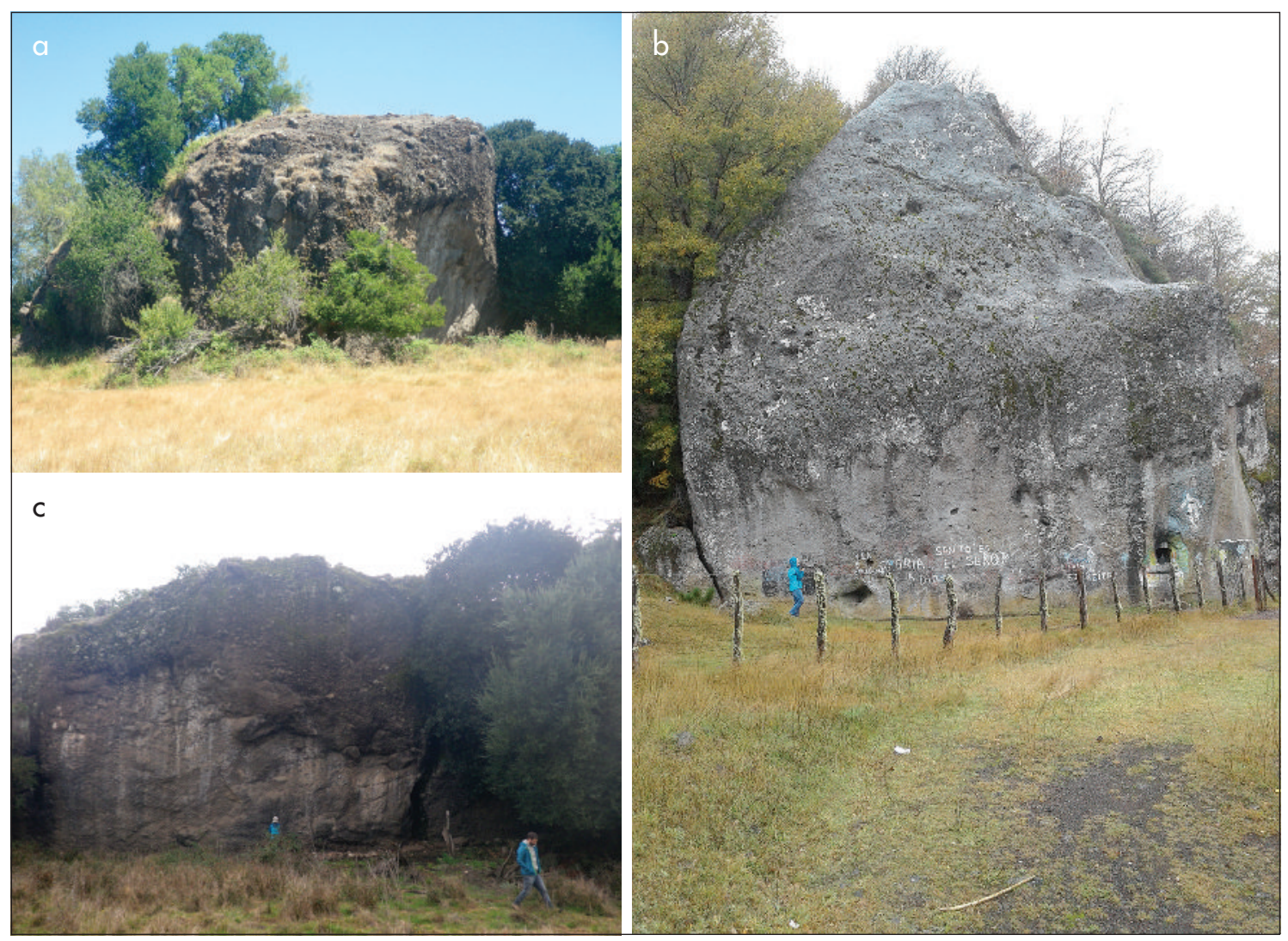

Figura 6. Bloques: a y b) Villucura-pinturas; c) Piedra santa de Retricura. (Fotografías: R. Campbell). Figure 6. Blocks: $\boldsymbol{a}$ and $\boldsymbol{b}$ ) Villucurapaintings; $c$ ) Sacred stone of Retricura. (Photographs: R. Campbell).

Guaiquivilo no son frecuentes en los sitios del sur de Chile, y por otro, ciertas similitudes con la evidencia presente en Neuquén (Argentina) hacen pensar que aquel representa un fenómeno más vinculado a procesos trasandinos o cordilleranos. Similar es el caso de los sitios Santa Bárbara 1, Torrentoso 01, Correntoso 01 y Paredón Luisa, presentes en las cercanías de pasos cordilleranos boscosos del extremo meridional del sur de Chile. Estos se asemejan más entre sí que con cualquier otro sitio del sur de Chile, dado que presentan motivos similares y comparten técnicas, colores y emplazamientos (pinturas rojas en alero). De hecho, sus diseños han sido asignados a la Tendencia Abstracta Geométrica Compleja y a la Modalidad del Ámbito Lacustre Boscoso, estilo definido para la Patagonia argentina (Podestá et al. 2008).

Si bien la cantidad de sitios de arte rupestre conocidos en el sur de Chile es baja en comparación con otras zonas, estos parecieran destacar precisamente por su alta variabilidad en términos iconográficos, técni- cos y espaciales. Esta diversidad podría reflejar que la producción de arte rupestre en estos distintos sectores responde a dinámicas muy específicas y de baja escala geográfica, al punto de que, quizás, no exista un lenguaje visual compartido en cuanto al arte rupestre. Por esta razón, a partir de la sistematización aquí presentada y considerando lo señalado respecto de la técnica de surco profundo y el motivo de la vulva, estimamos que no es factible asignar las manifestaciones rupestres del sur de Chile a una misma unidad estilística, ni tampoco proponer aún la existencia de estilos locales. No obstante, sí nos es posible plantear como hipótesis, a partir de la evidencia existente, que la manufactura de arte rupestre es un fenómeno de los últimos 2000 años, estando ausente previamente.

Uno de los aspectos por explorar en el futuro es la técnica de surcos profundos, la que parece tener cierta relevancia en el arte rupestre del sur de Chile. Por otra parte, dado que este trabajo se realizó mayormente a 
partir de una revisión bibliográfica, es fundamental complementarlo con actividades de terreno que permitan precisar la información en aspectos básicos, como la cuantificación de bloques y diseños. Esto podría afinar la búsqueda de semejanzas y diferencias entre motivos, aspectos que, debido a la falta de información, fueron explorados de forma muy sucinta. Lo anterior permitirá evaluar, por ejemplo, si el motivo de "vulva" -u otrostienen efectivamente algún grado de alcance regional.

Por último, es importantísimo desarrollar actividades que permitan el hallazgo de nuevos sitios, la reubicación y evaluación de sus materiales asociados, como también la revisión contextual de aquellos espacios que corresponden a piedras tacitas y piedras santas.

Agradecimientos Al Proyecto Fondecyt No 11150397 y a todo su equipo de investigación. A Leonor Adán, Eliana Cifuentes, Luis Espinoza, Javier Ibar, Carlos Lonconado, Rodrigo Mera, Doina Munita, Francisco Rivera, Matthias Strecker, Andrés Troncoso y Simón Urbina. A los evaluadores por sus importantes comentarios.

\section{NOTAS}

${ }^{1}$ Alberto Plagemann, explorador y fotógrafo chileno -tratado a veces como alemán- realizó viajes de reconocimiento geológico a distintos puntos de Chile (Steffen 1910: 228-229, Rodríguez 1985: 298). Presentó su trabajo sobre los "Pintados de Chile" en el xiv Congreso Americanista (Stuttgart, 1904), siendo publicado en alemán en 1906. Sobre esta obra se señala que fue traducida por Percy Dauelsberg (Álvarez 1994: 10, Rivera 1995-1996: 21). Hemos consultado a investigadores de la Universidad de Tarapacá, pero no se tiene pista alguna sobre dicha traducción.

${ }^{2}$ En un sentido mayormente anecdótico, Oyarzún (1910: 41) indica que los petroglifos se ubican en el fundo Quinchol de propiedad de L. A. Rivera. Este mismo fundo y su dueño, aunque identificándolo como Alfredo Riveros, fueron conocidos en 1894 por Verniory (2001: 332-338) días antes de su viaje a la cordillera de Lonquimay (2001: 340-349). Dicha aventura, si bien inédita hasta 1975, nos entrega la referencia presencial más temprana respecto a la piedra santa de Retricura, a la que nos referimos en la Discusión y que fue descrita científicamente por primera vez por Oyarzún (1924). Luis Alfredo Rivera Olavarría fue diputado del Partido Liberal Democrático por Temuco, Imperial y Llaima de 1909 a 1915.

${ }^{3}$ Nos parece importante destacar que Gordon logró reubicar los dos bloques de los Petroglifos del Llaima descritos por Oyarzún (1910). Sin embargo, con el afán de protegerlos, decidió que "Para resguardar el monumento no se indica su posición exacta. El dato se encuentra en poder del Director del Museo Nacional de Historia Natural de Santiago, a dis- posición de los investigadores que deseen realizar estudios en el lugar" (Gordon 1980: 69). Dicha dirección era ejercida en aquel momento por Grete Mostny. Hemos consultado a investigadores del museo y dicha información no existe hoy. No obstante, esto no impidió que en la década de 1990, a instancias del concejal y luego alcalde de Curacautín Gustavo Weise, uno de estos bloques fuese reencontrado y a continuación trasladado a la Plaza de Armas de Curacautín (Piedra de Reunión 2011: 12). Allí fue estudiado por nosotros. Desconocemos el paradero del otro bloque.

${ }^{4}$ Si bien, la publicación de Schobinger está fechada en 1957, en esta se hace alusión (1957: 211) al hallazgo de arte rupestre en el Valle de Calabozos de principios de 1958.

${ }^{5}$ Aunque cualquier punto puede ser considerado como parte de un camino a otro punto.

\section{REFERENCIAS}

Adán, L. 2014. Los reche-mapuche a través de su sistema de asentamiento (s. XV-XVII). Tesis para optar al grado de Doctora en Historia mención Etnohistoria, Departamento de Ciencias Históricas, Universidad de Chile.

Adán, L., Mera, R. \& Godoy, M. 2005 Ms. Reconocimiento arqueológico de la localidad de Colún. Estudio solicitado por WWF-Chile para proyecto Reserva Costera Valdiviana.

Adán, L., Mera, R., Bahamondes, F. \& Donoso, S. 2007. Síntesis arqueológica de la cuenca del río Valdivia: proposiciones a partir del estudio de sitios alfareros prehispánicos. Revista Austral de Ciencias Sociales 12: 5-34.

Adán, L., Mera, R., Navarro, X., Quiroz, D., Campbell, R. \& SÁnCHEZ, M. 2016. Historia prehispánica en la región Centro-Sur de Chile: cazadores-recolectores holocénicos y comunidades alfareras. En Prehistoria en Chile. Desde sus primeros habitantes hasta los incas, F. Falabella, C. Aldunate, M. Uribe \& L. Sanhueza, Eds., pp. 401-441. Santiago: Universitaria.

Aldunate, C., Berenguer, J. \& Castro, V. (Eds.) 1985. Estudios en arte rupestre. Primeras jornadas de arte $y$ arqueología: el arte rupestre en Chile. Santiago: Museo Chileno de Arte Precolombino.

Aldunate, C. 1989. Estadio alfarero en el sur de Chile. En Prehistoria. Desde sus orígenes hasta los albores de la conquista, J. Hidalgo, V. Schiappacasse, H. Niemeyer, C. Aldunate \& I. Solimano, Eds., pp. 329-348. Santiago: Andrés Bello.

Álvarez, L. 1994. Discurso-homenaje que rindió la Sociedad Chilena de Arqueología a Percy Dauelsberg Hahmann en el XiII Congreso Nacional de Arqueología Chilena, en Antofagasta el 10 de octubre de 1994. Chungara 26 (1): 8-10.

Álvarez, M. \& Fiore, D. 1995. Recreando imágenes: diseño de experimentación acerca de las técnicas y los artefactos para realizar granados de arte rupestre. Cuadernos del Instituto Nacional de Antropología y Pensamiento Latinoamericano 16: 215-239. 
Ampuero, G. 1985. El arte rupestre en el Norte Chico, análisis y proposiciones metodológicas. En Estudios en arte rupestre, C. Aldunate, J. Berenguer \& V. Castro, Eds., pp. 413-416. Santiago: Museo Chileno de Arte Precolombino.

Artigas, D. \& Muñoz, C. 2015. Arte rupestre en el curso medio de río Ibáñez: retomando el camino de la interacción de las manifestaciones artísticas al contexto regional. En Actas del XIX Congreso Nacional de Arqueología Chilena, pp. 507-514. Santiago: Andros.

Augusta, F. 1916a. Diccionario Araucano-Español y EspañolAraucano. Tomo I. Santiago: Universitaria.

Augusta, F. 1916b. Diccionario Araucano-Español y EspañolAraucano. Tomo II. Santiago: Universitaria.

Barberena, R., Romero, G., Lucero, G., Fernández, M. V. \& Quiroga, M. N. 2017. Espacios internodales en Patagonia septentrional: biogeografía, información y mecanismos sociales de interacción. Estudios Atacameños 56: 57-75.

Barros Arana, D. 1884. Historia Jeneral de Chile. Tomo I. Santiago: Rafael Jover.

Barros Grez, D. 1900. Interpretación de la inscripción prehistórica de la Casa Pintada en el Alto Tinguiririca. Primera Reunión del Congreso Científico Latino Americano, Tomo v, pp. 197-202. Buenos Aires: Compañía Sud Americana de Billetes de Banco.

Bate, F. 1970. Primeras investigaciones sobre el arte rupestre de la patagonia chilena. Anales del Instituto de la Patagonia 1: 17-25.

Bate, F. 1971. Primeras investigaciones sobre el arte rupestre de la Patagonia chilena (segundo informe). Anales del Instituto de la Patagonia 2: 33-41.

Berdichewsky, B. 1968. Excavación en la Cueva de los Catalanes (Provincia de Malleco). Boletín de Prehistoria de Chile 1: 33-83.

Berenguer, J. 1986. El arte rupestre en Chile. Santiago: Museo Chileno de Arte Precolombino

Blanco, R. V., Miotti, L. \& CARden, N. 2015. El arte rupestre del nordeste de la meseta de Somuncurá: caracterización inicial e integración regional. Mundo de Antes 8: 83-103.

BörgeL, R. 1983. Geomorfología. Santiago: Instituto Geográfico Militar.

Bufoland, 2015. El petroglifo o Namuncura de Río Bueno. http://bufoland.blogspot.com/2015/07/el-petroglifo-onamuncura-de-rio-bueno.html

Calvo, M. 1968. Leyendas de Calafquén. Costumbres mapuches. Santiago: Arancibia Hermanos.

Campbell, R., Roa, C., Delgado, A., Dávila, C., Gajardo, J., López, M., Martínez, I., Palma, G., Peñaloza, A., Andrade, P., Godoy, C., Inostroza, H., Cortés, C., GonZÁlez, C. \& ZÚÑIGA, M. 2017. Cueva de los Catalanes: nuevas investigaciones, 60 años después (Araucanía, Chile). Póster presentado en las x Jornadas de Arqueología de la Patagonia. Puerto Madryn, Argentina.

Campbell, R., Roa, C. \& Santana-Sagredo, F. 2018. Más sureño que los porotos. Primeros fechados 14C AMs para el sitio Cueva de los Catalanes. Boletín de la Sociedad Chilena de Arqueología 48: 85-89.

CAÑAs, A. 1902. La religión en los pueblos primitivos: el culto de la piedra en Chile y cómo se hallaba difundido por el globo. Actes de la Sociéte Scientifique du Chili xıI: 177-250.

Castelleti, J. 2007. El arte rupestre en la zona boscosolacustre cordillerana del sur de Chile y sus relaciones con las regiones vecinas. Boletín de la Sociedad Chilena de Arqueología 40: 57-71.

Cervellino, M. 1985. Evaluación del arte rupestre en la III Región de Atacama. En Estudios en arte rupestre, C. Aldunate, J. Berenguer \& V. Castro, Eds., pp. 355-371. Santiago: Museo Chileno de Arte Precolombino.

De la CERDA, L. 1935. Comunicación sobre los restos arqueológicos de la cordillera de Millahue. Revista Universitaria 20 (3): 281-284.

DiARIO Ilustrado, 1958. Se acentúa la existencia de ciudades milenarias en la zona de "Huanquivilo" y de los "Calabozos". 11 de abril de 1958, pp. 1 y 2. Santiago.

Dillehay, T. \& Ocampo, C. 2016. Prospecciones y excavaciones. En El Paso Vuriloche. Chile-Argentina. Ruta de los Jesuitas, T. Dillehay \& C. Ocampo, Eds., pp. 13-27. Puerto Montt: Universidad Austral de Chile.

Doмeyкo, I. 1903. Jeolojía. Tomo Quinto. Santiago: Cervantes.

ERCILLA. 1959. Enigma para arqueólogos. No 1250 del 6-mayo1959. Santiago.

Espinoza, L. 2017. Hualqui: el misterio de los petroglifos del Cerro de la Costilla, un patrimonio en peligro. Concepción: Ícaro.

Fernández, J. 1974-1976. Estudios sobre el arte rupestre de la provincia del Neuquén. Anales de Arqueología y Etnología 29-31: 5-36.

FERnÁndeZ, J. 2000 [1979]. Las piedras con marcas de la cordillera del Viento. Arte rupestre en el departamento Minas, Neuquén, Argentina. Buenos Aires: Sociedad Argentina de Antropología.

FIORE, D. 2011. Materialidad visual y arqueología de la imagen. Perspectivas conceptuales y propuestas metodológicas desde el sur de Sudamérica. Boletín del Museo Chileno de Arte Precolombino 16 (2): 101-119.

FoncK, F. 1870. Die Indier des südlichen Chile von sonst und jetzt. Zeitschrift für Ethnologie 2: 284-294.

Fonck, O. 1965. Construyamos arcas. Santiago: Orbe.

Fontecilla, A. 1936. Contribución al estudio de los petroglifos cordilleranos. Revista Chilena de Historia Natural xL: 69-72.

GAJARDO, R. 1994. La vegetación natural de Chile: clasificación y distribución geográfica. Santiago: Universitaria.

García, J. 2007 Ms. Fichas de registro de Arte Rupestre panel. Golledge, R. 2003. Human wayfinding and cognitive maps. En Colonization of unfamiliar landscapes. The archaeology of adaptation, M. Rockman \& J. Steele, Eds., pp. 25-43. Nueva York: Routledge.

González, J. 1986. Villarrica: historia inédita. Temuco: Talleres Telstar. 
González, J. 2012. Catastro arqueológico arte rupestre en la Reserva Nacional Río de los Cipreses. Santiago: Andros.

Gordon, A. 1980. Cura-Cahuin, una visión nueva de los petroglifos del Llaima. Boletín del Museo Nacional de Historia Natural 37: 61-74.

Gordon, A. 1982. Cura-Cahuiñ, una visión nueva de los "petroglifos del Llaima". En Actas del viII Congreso de Arqueología Chilena, p. 82. Valdivia: Kultrun.

Guevara, T. 1911. Folklore araucano: refranes, cuentos, cantos, procedimientos industriales, costumbres prehispánicas. Santiago: Cervantes.

Guevara, T. 1916. La mentalidad araucana. Anales de la Universidad de Chile 74 (139): 147-196.

Gutiérrez, R. 2016 Ms. Primeros resultados arte rupestre Cueva de los Catalanes.

Gutiérrez, R. \& Moya, F. 2016. Arte rupestre en Cueva de los Catalanes: una aproximación y nuevas interrogantes al arte rupestre de la Araucanía (Ix región de Chile). Póster presentado en las x Jornadas de Arqueología de la Patagonia. Puerto Madryn, Argentina.

Ilustre Municipalidad de Colbún, 2003. Arte rupestre en la cordillera de los Andes. Talca: Gutenberg.

InostrozA, J. \& SÁnchez, M. 1994. Arqueología del Parque Nacional Conguillío: modalidades de ocupación del espacio. En Patrimonio arqueológico en áreas silvestres protegidas, M. Massone \& R. Seguel, Eds., pp. 107-136. Santiago: Centro de Investigaciones Diego Barros Arana.

Inostroza, J., Riffo, P., Sánchez, M. \& Valdebenito, B. 1983. Petroglifos de la Meseta de Maloñehue. Comuna de Lonquimay, Ix Región, Chile. Frontera 2: 43-58.

Inostroza, J., Riffo, P. \& Sánchez, M. 1984. Maloñehue 1: un sitio de petroglifos en la comuna de Lonquimay, IX Región, Chile. Cultura, Hombre y Sociedad 1: 118-136.

IRIBARREN, J. 1973a. Geoglifos, pictografías y petroglifos de Chile. Boletín del Museo Arqueológico de La Serena 15: 133-159.

IRIBARREN, J. 1973b. Pictografías en las Provincias de Atacama y Coquimbo, Chile. Boletín del Museo Arqueológico de La Serena 15: 115-132.

Jackson, D., Artigas, D. \& Cabello, G. 2001. Trazos del Choapa: arte rupestre en la cuenca del río Choapa. Una perspectiva macroespacial. Santiago: LOM.

Labarca, R., Mena, F., Prieto, A., Dupradou, T. \& Silva, E. 2016. Investigaciones arqueológicas en torno a los primeros registros de arte rupestre en Morro Vilcún. Boletín del Museo Chileno de Arte Precolombino 21 (2): 65-80.

LARA, M. 2014. Ruinas y lugares arqueológicos en la comuna de Purén. En <http://turismocomunapuren.blogspot. cl/2014/12/ruinas-y-lugares-arquelogicos-en-la.html> [consultado: 02-02-2020].

Lara, R. 2002. Petroglifos de Colbún. Boletín de Historia y Geografía 16: 15-27.

Lara, A., Solari, M., Prieto, M. \& PeÑa, M. 2012. Reconstrucción de la cobertura de la vegetación y uso del suelo hacia 1550 y sus cambios a 2007 en la ecorregión de los bosques valdivianos lluviosos de Chile ( $\left.35^{\circ}-43^{\circ} 30^{\prime} \mathrm{S}\right)$. Bosque 33 (1):13-23.

Lucero, V. \& Mena, F. 2000. Arte rupestre del Río Ibáñez (xi Región): un análisis cuantitativo exploratorio. En Desde el país de los gigantes. Perspectivas arqueológicas en Patagonia, J. Belardi, F. Carballo \& S. Espinosa, Eds., Tomo I, pp. 415-427. Río Gallegos: Universidad Nacional de la Patagonia Austral.

Luebert, F. \& Pliscoff, P. 2006. Sinopsis bioclimática y vegetacional de Chile. Santiago: Universitaria.

Marsh, E. 2017. La fecha de la cerámica más temprana en los Andes sur. Una perspectiva macrorregional mediante modelos bayesianos. Revista del Museo de Antropología, suplemento especial 1: 83-94.

MedinA, J. 1882. Los aborijenes de Chile. Santiago: Gutenberg.

Menard, A. 2017. The political vitality of mapuche stones: heteronomy and political decision-making. Journal of Material Culture 22 (3): 334-347.

Menghin, O. 1957. Estilos de arte rupestre de Patagonia. Acta Praehistórica I: 57-87.

Menghin, O. 1959-1960. Estudios de prehistoria araucana. Acta Praehistórica III-IV: 49-120.

Menghin, O. 1964. Eine bolivianisch-chilenische Gruppe von Felsgravierungen. En Festschrift für Ad. E. Jensen, E. Haberland, M. Schuster \& H. Straube, Eds., Tomo 2, pp. 379-385. Múnich: K. Renner.

Mera, R. \& Munita, D. 2008 Ms. Informe arqueológico. Proyecto "Parque Futangue". Comuna de Futrono. Provincia del Ranco. Región de Los Ríos.

Montandon, R. 1958. Los petroglifos de Parral. Zig-Zag, 15 de febrero de 1958: 22-25.

Montané, J. 1965-1966. Pictografías y petroglifo de Villucura (Prov. de Biobío). Revista Universitaria 50-51 (2): 377-382.

Morales, A., Mella, C. \& González, P. 2015. Arte rupestre en la Región del Maule. Huellas de un pasado desconocido. Talca: Gutenberg.

Mostny, G. \& Niemeyer, H. 1983. Arte rupestre chileno. Santiago: Departamento de Extensión Cultural del Ministerio de Educación.

Moya, F., Sierralta, S. \& Gutiérrez, R. 2019. Nuevo registro de arte rupestre en pasos cordilleranos: Paredón Luisa (Cochamó, Región de Los Lagos, Chile). Magallania 47 (2): 175-182.

Mueller, G. 1958. Los petroglifos del Valle de Calabozos. Provincia de Linares, Chile. Boletín de la Sociedad de Biología de Concepción, Tomo xxxiII: 155-160.

Museo Regional de La Araucanía, 1985. Proyecto investigación arte rupestre. Boletín de la Sociedad Chilena de Arqueología 3: 4.

Niemeyer, H. 1975. Guía del arte rupestre de Chile. Santiago: Editora Nacional Gabriela Mistral.

Niemeyer, H. 1979. Variación de los estilos de arte rupestre en Chile. En Actas del VII Congreso de Arqueología de Chile, Volumen II, pp. 649-660. Santiago: Kultrun. 
Niemeyer, H. \& Ballereau, D. 1998. Los petroglifos del cerro La Silla, Región de Coquimbo. Chungara 28 (1-2): 277-318.

Niemeyer, H. \& Ballereau, D. 2004. Arte rupestre del Río Grande, cuenca del río Limarí, Norte Chico, Chile. Chungara 36 (1): 37-101.

Niemeyer, H. \& León, V. 2001. Arte rupestre precolombino en el Tinguiririca. Provincia de Colchagua, Sexta Región de Chile. Santiago: Fondart, Ministerio de Educación.

Niemeyer, H. \& Montané, J. 1968. El arte rupestre indígena en la zona centro-sur de Chile. En Actas y Memoria del XXXVII Congreso Internacional de Americanistas, Tomo II, pp. 419-452. Buenos Aires: Libart.

Niemeyer, H. \& Weisner, L. 1972-1973. Los petroglifos de la cordillera andina de Linares (Provincia de Talca y Linares, Chile). En Actas del vi Congreso de Arqueología Chilena. Boletín de Prehistoria, número especial: 406-468.

Oliver, C. 1935. El campo arqueológico de Millahue. Revista Universitaria 20 (4-5): 597-599.

Oyarzún, A. 1910. Los Petroglifos del Llaima. Boletín del Museo Nacional de Chile, Tomo II (1): 38-48.

Oyarzún, A. 1924. La Piedra Santa de Retricura. Publicaciones del Museo de Etnología y Antropología de Chile IV (1-2): 137-145.

Pérez, A. \& SAlaberry, G. 2014. Las pinturas rupestres del sitio Paredón de Bello (Cordón Chapelco), San Martín de los Andes, Neuquén, Argentina. Boletín del Museo Chileno de Arte Precolombino 19 (2): 77-93.

PIEDRA DE REUNión. 2011, Nº 1. Curacautín.

Plagemann, A. 1906. Über die chilenischen "Pintados". Beitrag zur Katalogisierung und vergleichenden Untersuchung der südamerikanischen Piktographien. Internationaler Amerikanisten-Kongress (Stuttgart 1904), Volumen 14. Stuttgart: W. Kohlhammer.

Podestá, M., Bellelli, C., Labarca, R., Albornoz, A., Vasini, A. \& Tropea, E. 2008. Arte rupestre en pasos cordilleranos del bosque andino patagónico (El Manso, Región de Los Lagos y Provincia de Río Negro, ChileArgentina). Magallania 36 (2): 143-153.

Reyes, M. 2016. Guaquivilo. Arte en la precordillera de la Provincia de Linares. <https://petroglifosguaiquivilo5. webnode.es/> [consultado: 03-02-2020].

Rivera, M. 1995-1996. La secuencia de Azapa del centro sur andino: una revisión de las contribuciones de Percy Dauelsberg Hahmann. Diálogo Andino 14-15: 17-30.

Rodríguez, H. 1985. Historia de la fotografía en Chile. Registro de daguerrotipistas, fotógrafos, reporteros gráficos y camarógrafos 1840-1940. Boletín de la Academia Chilena de la Historia 96: 189-340.

Romero, G. 2016. La clasificación de las pinturas rupestres del noreste de Neuquén, Patagonia septentrional. En Imágenes rupestres, lugares y regiones, F. Oliva, A. M. Rocchieti \& F. S. Banfi, Eds., pp. 441-452. Rosario: Centro de Estudios Arqueológicos Regionales-Centro de Arqueología HistóricaCooperadora Asociación José Pedroni-Agencia Nacional de Promoción Científica y Tecnológica.
Romero, G. \& Re, A. 2014. Representaciones rupestres del noreste de Neuquén (Patagonia septentrional). Primeras tendencias espaciales y temporales. Comechingonia 18 (1): 73-92.

Sanguinetti, N. 1970. Petroglifos del Cerro Quiñe (Provincia de Linares). Linares: Museo de Linares.

Sarricolea, P., Herrera-Ossandón, M. \& Meseguer-Ruiz, Ó. 2018. Climatic regionalisation of continental Chile. Journal of Maps 13 (2): 66-73.

Schindler, H. \& SCHIndler-YÁÑEZ, M. 2006. La piedra santa del río Lumaco. En Acerca de la espiritualidad mapuche, $\mathrm{H}$. Schindler, Ed., pp. 11-67. Múnich: Meidenbauer.

Schobinger, J. 1956. El arte rupestre de la Provincia de Neuquén. Anales de Arqueología y Etnología 13: 115-227.

Schobinger, J. 1957. Arqueología de la Provincia de Neuquén. Estudio de los hallazgos mobiliares. Anales de Arqueología y Etnología 13: 6-232.

Sepúlveda, M. \& Valenzuela, D. 2012. Rock art in Chile, 2005-2009. En Rock art studies: news of the world IV, P. Bahn, N. Franklin \& M. Strecker, Eds., pp. 286-398. Oxford: Archaeopress Archaeology.

Sepúlveda, M., Cabello, G. \& Valenzuela, D. 2016. Rock art in Chile (2010-2014). En Rock art studies: news of the world v, P. Bahn, N. Franklin, M. Strecker \& E. Devlet, Eds., pp. 349-364. Oxford: Archaeopress Archaeology.

Steffen, H. 1910. Contribución de los alemanes al estudio de la jeografía y jeología de Chile. En Los Alemanes en Chile. Homenaje de la Sociedad Científica Alemana de Santiago a la Nación Chilena en el centenario de su independencia. Tomo I. Santiago: Universitaria.

Stehberg, R. 1980. Diccionario de sitios arqueológicos de Araucanía. Publicación ocasional 31. Santiago: Museo Nacional de Historia Natural.

Stolp, K. 1899. Indianische Zeichen aus der Kordillere Chiles aufgefunden. Verhandlungen des Deutschen Wissenschaftlichen Vereins zu Santiago de Chile 2 (1): 35-37.

The Nature Conservancy. 2018. Reserva Costera Valdiviana. Atracciones. <http://www.reservacosteravaldiviana.cl/es/ visitenos/atracciones> [consultado: 03-02-2020].

Troncoso, A. 2002. Deconstruyendo el signo escudo y el estilo Aconcagua. Reconstruyendo la problemática rupestre en Chile Central. Boletín de la Sociedad Chilena de Arqueología 33-34: 12-26.

Troncoso, A., Armstrong, F., Vergara, F., Urzúa, P. \& LARACH, P. 2008. Arte rupestre en el valle El Encanto (Ovalle, Región de Coquimbo): hacia una revaluación del sitio-tipo del Estilo Limarí. Boletín del Museo Chileno de Arte Precolombino 13 (2): 9-36.

Troncoso, A., Criado-Boado, F. \& Santos-Estévez, M. 2011. Arte rupestre y códigos espaciales: un caso de estudio en Chile Central. Chungara 43 (2): 161-176.

Troncoso, A., Armstrong, F. \& Basile, M. 2017. Rock art in Central and South America: social settings and regional diversity. En The Oxford handbook of the archaeology and 
anthropology of rock art, B. David \& I. J. McNiven, Eds., pp. 273-314. Oxford: Oxford University Press.

Troncoso, A., Armstrong, F. \& Nash, G. (Eds.) 2018. Archaeologies of rock art: south american perspectives. Londres: Routledge.

Van de Maele, M. 1966. Peñascos y petroglifos de Río Bueno. En Investigaciones arqueológicas. Investigaciones históricas 1964-1965, 1965-1966. Valdivia: Universidad Austral de Chile.

VAn de Maele, M. 1968. Mapa Histórico-Arqueológico de la Provincia de Valdivia. En Investigaciones arqueológicas. Investigaciones históricas. Valdivia: Universidad Austral de Chile.

VEA. 1958. Ciudad milenaria anterior a la época incaica esconde su secreto en Linares. No 990 del 17 de abril de 1958, p. 2. Santiago.
Vergara, C. 1972-1973. Petroglifos de las Piedras de las Marcas. En Actas del vi Congreso de Arqueología Chilena. Boletín de Prehistoria, número especial: 471-485.

Vergara, J. 1990. Los petroglifos del río Itata. Museos 7: 19-20. Vergara, J. 1991. Conjuntos arqueológicos pétreos en la viII Región. Museos 9: 14-15.

Vergara, F. \& Troncoso, A. 2015. Rock art, technique and technology: an exploratory study of hunter-gatherer and agrarian communities in pre-hispanic Chile (500 to 1450 CE). Rock Art Research 32 (1): 31-45.

Verniory, G. 2001. Diez años en Araucanía, 1889-1899. Santiago: Pehuén.

VILLALÓN, L. 1964. Informe sobre petroglifos en la provincia de Concepción. Arqueología de Chile central y áreas vecinas. Publicación de los trabajos presentados al III Congreso Internacional de Arqueología Chilena, pp. 131 y 132. Santiago. 